
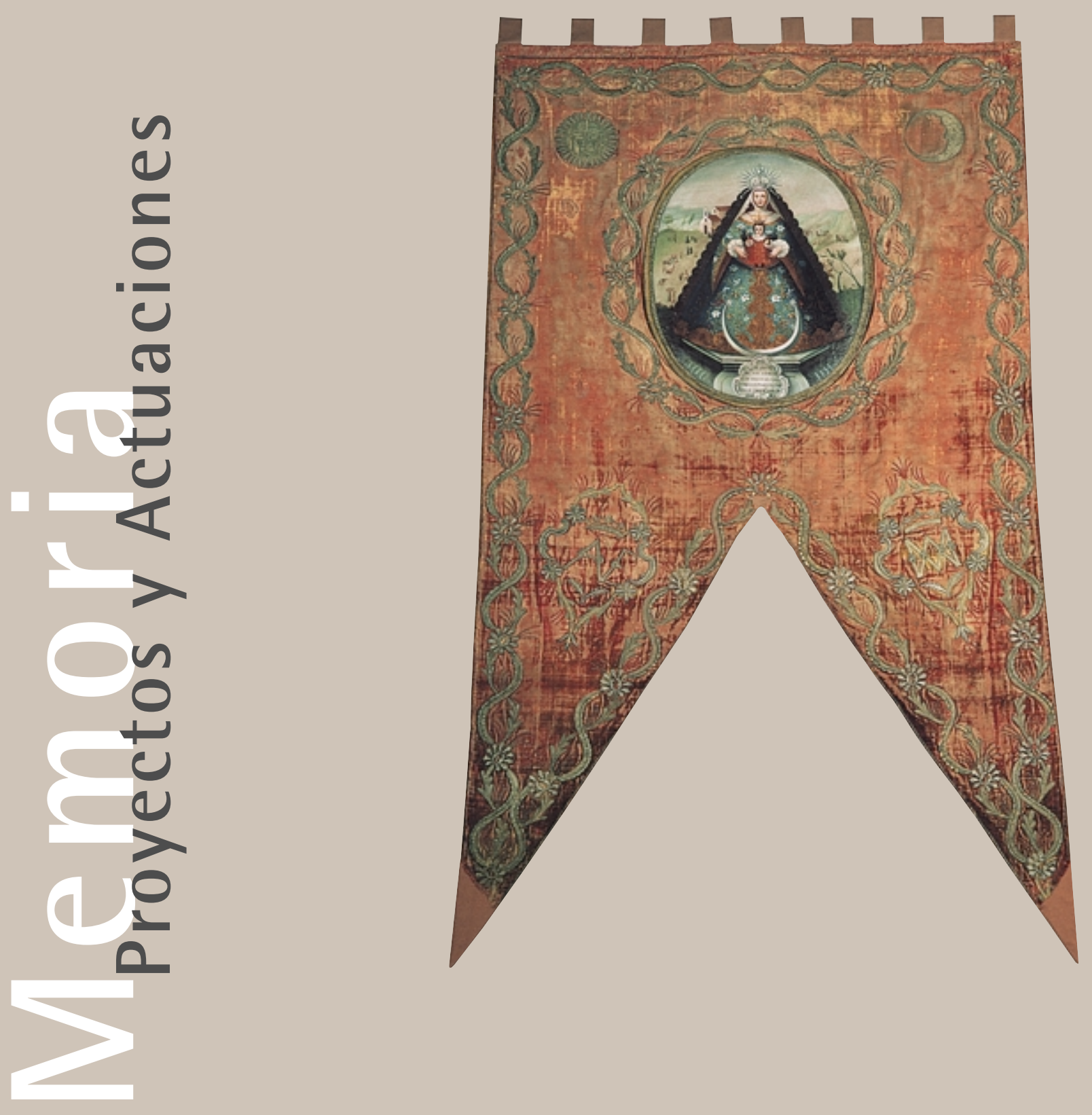

\title{
Intervención del Simpecado viejo de la Virgen del Rocío de la Hermandad de Villamanrique de la Condesa
}

\author{
Gabriel Ferreras Romero \\ Rocío Magdaleno Granja \\ Lourdes Fernández González \\ Francisco Gutiérrez Montero \\ Lourdes Martín García \\ Marta Sameño Puerto \\ Raniero Baglioni
}


$\frac{\frac{\pi}{0}}{\sum^{2}}$

Copia de la Virgen del Rocío del siglo XVIII. Colección particular

Romería del Rocío, principios del siglo $X X$
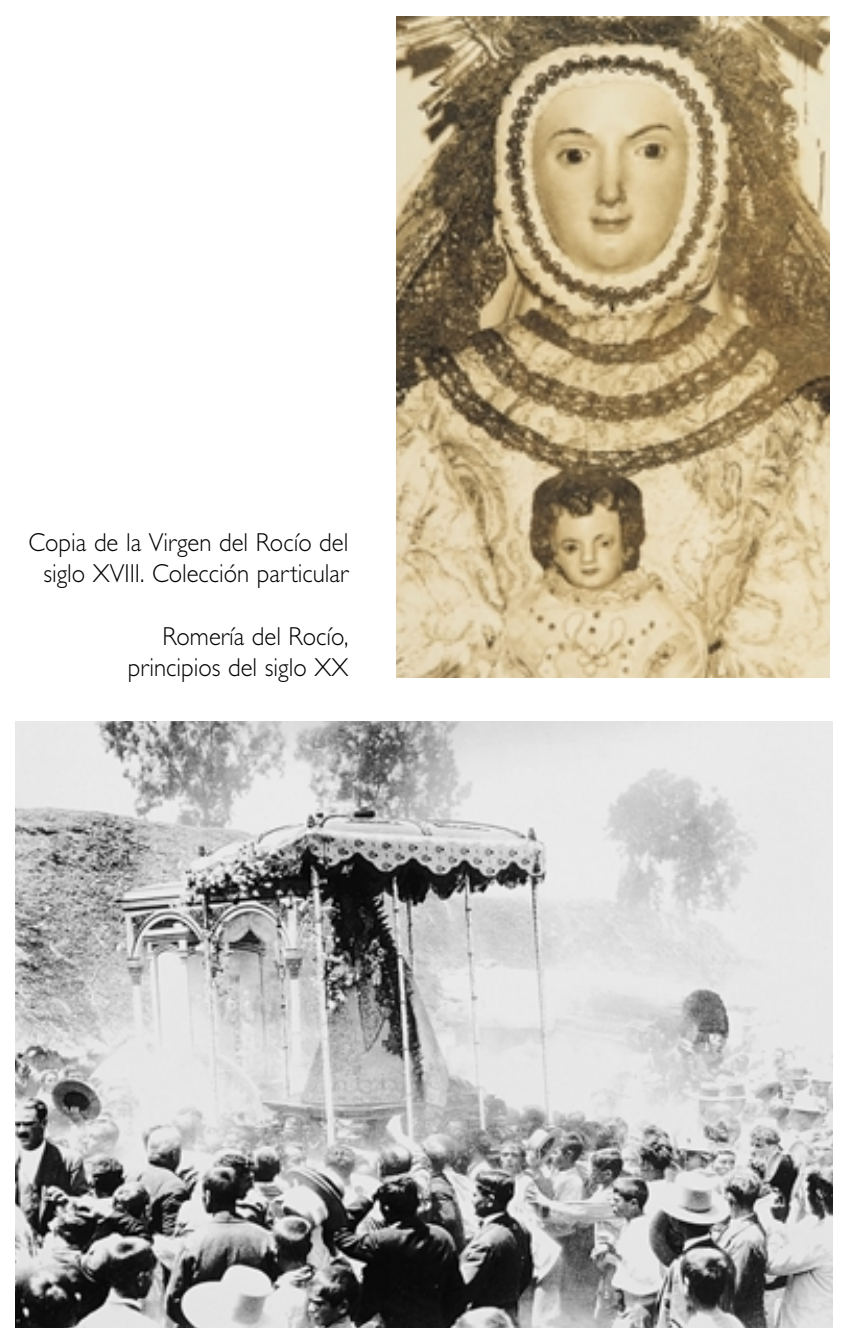

ESTUDIO HISTÓRICO-ARTÍSTICO

El origen histórico de la devoción a la Virgen del Rocío, de todos conocida, se remonta al rey Alfonso $X$, el Sabio, quién después de la reconquista islámica se reservó unos terrenos de caza (pertenecientes al reino de Sevilla) que llegaban desde Mures (la actual Villamanrique) hasta el límite con las tierras de Niebla. Este rey, devoto de la Virgen, como sabemos por las Cantigas pudo ser el que edificó en estos lugares una ermita dedicada a Santa María que después daría lugar a llamarse de las Rocinas. La ermita aparece documentada por primera vez en el "Libro de la Montería" de Alfonso Xl, según algunos tratadistas y también se nombra por primera vez en este mismo libro la población de Mures (documento fechado el 26 de octubre de 1388). Esta población la deja en heredad Alfonso $X$ hacia 125 I- 1253 a veinte monteros o cazadores reales'.

Años más tarde se producen casi con toda seguridad una serie de invasiones moriscas a las comarcas del Aljarafe y de la Marisma que profanaban los templos e imágenes cristianas. Por ello se escondieron y ocultaron muchas representaciones de la Virgen aunque ello supusiera quedar apartadas y olvidadas del culto religioso.
Ya entrado el siglo XV cuenta la leyenda que el montero Gregorio Medina de la población de Villamanrique, encontró en el hueco de un viejo acebuche la imagen de la Virgen del Rocío en el término de la villa de Almonte, cerca de la legua denominada Coto de Lomo de Grullo, en el sitio llamado de la Rocina ${ }^{2}$.

Pero los primeros datos documentales o de archivo que demuestran la existencia de una gran devoción a la Virgen del Rocío por los vecinos de Villamanrique están registrados en los libros de partidas de defunciones de la antigua parroquia de Santa María Magdalena de esta localidad. (Libro I, folios 97, 124, 173 y Libro II folios 32, 58) de los años 1708, 1712, 1723 , etc... donde se recogen una serie de encargos de misas de difuntos que dice: "sean dichas por deseo y última voluntad de los devotos o Hermanos difuntos en el altar de Ntra. Sra. del Rocío que ostenta en la iglesia parroquial" 3 .

Así mismo aparecen donaciones de varios reales de vellón para el mantenimiento del culto de la capilla de la Virgen. También en los Libros de Bautismo de la parroquia se encuentra, a partir de los primeros años del siglo XVIII y durante todo el siglo XIX, la agregación del nombre de "Rocío" al primer nombre del bautizado, sin excepción entre hombre o mujer ${ }^{4}$. Este dato demuestra el fuerte fervor de los manriqueños hacia esta advocación mariana. Además se sabe por antiguo protocolo que existía una capellanía bajo el nombre de Ntra. Sra. del Rocío de Villamanrique que poseía una serie de tierras o propiedades, "Son unas hazas de tierra de pan sembrar, al sitio que nombran la Mata, término de esta villa, que lindan con tierras del Concejo de dicha villa y por un lado con tierras de Juan Solís y por otra con el Palacio de Lomo de Grullo" 5.

Con toda seguridad existiría a finales del siglo XVII o principios del XVIII en la antigua parroquia de Villamanrique una pequeña escultura o imagen de la Virgen del Rocío a la que se le daba culto y se le hacían donaciones para el mantenimiento de su capilla, copia de la original y primitiva reformada en época barroca y que se hallaba en la ermita del Rocío. Con el pasar del tiempo y la renovación de la parroquia hasta principios del siglo XIX, esta reproducción de la Virgen pasó probablemente a casa de algún particular, quedándose solamente la representación de esta pequeña imagen, con su mirada al frente, en la pintura que lleva el Simpecado que actualmente hemos restaurado en el Instituto Andaluz de Patrimonio Histórico. Desgraciadamente tampoco se conservan ningunas reglas o estatutos de esta época, pero si cabe suponer la existencia de unas normas más primitivas de dotación legal, como asegura don Manuel Carrasco en su obra "Historiando el Rocío", situando cronológicamente los posibles estatutos hacia 1742 y 17486 . Los primeros estatutos que se conservan en diversas publicaciones impresas, son de 1913 siendo presidente de la Hdad. Don Rafael Reyes. Aprobándose posteriormente las primeras reglas adaptadas al arzobispado de Sevilla en 1925 y siendo la primera Junta de Gobierno que aprueba la autoridad eclesiástica de Sevilla la del ejercicio 1926-1927 7. 
Otro dato importante a tener en cuenta, es el orden que ocupa en la peregrinación a la aldea del Rocío, que ha conservado siempre el primer lugar hasta nuestros días y que le reconocen las reglas de la Hdad. de Almonte de 1758, además establecen que todas la Hermandades que peregrinaban al Rocío en aquella época tenían sus reglas o modo de gobierno.

Centrándonos ya en el origen de esta obra, el denominado "Simpecado viejo" tenemos que encuadrarlo cronológicamente en la primera mitad del siglo XVIII por varios motivos:

El primero, por la inscripción que aparece en la parte inferior de la pintura, en una especie de cartela de corte y estilo muy barroco, con enmarque de motivos decorativos de rocallas, propias de los inicios del siglo XVIII, en un principio creíamos que esta cartela podía ser un repinte sobre la pintura original, pero por medio de luz ultravioleta se confirmó su autenticidad. La inscripción en letra mayúscula y abreviada dice: "se hizo este retrato de Ntra. Sra. del Rocío y se bordó el Simpecado, siendo Hno. Mayor Juan Ponze a devoción suya y de varios devotos".

Ya en 1969 Don Manuel Carrasco Díaz en su libro anteriormente citado fecha esta obra entre 1725 y 1735 , debido a la consulta de los libros del archivo parroquial donde relaciona a Doña Dolores Arenas Ponze como descendiente en línea directa con Juan Ponze diciéndonos que sería Hno. Mayor de esta fervorosa Hdad. en estos años. Además existe una coplilla de corte popular que se cantaba en Villamanrique, donde en su estribillo se habla de un "Simpecado nuevo" y también hace alusión al susodicho Juan Ponze:

\section{"Dice Juanchito Ponze \\ con parsimonia \\ que el Simpecado nuevo \\ lo lleva Antonia".}

Lo que demuestra que antes existía ya, otro Simpecado más antiguo o primitivo ${ }^{8}$.

También puede fechar esta obra la existencia de un grabado datado en 1754, donde aparece la siguiente inscripción: "Verdadero retrato de Ntra. Sra. del Rocío, término de Almonte, rezando una salve ante esta Sra., se ganan 120 días de indulgencia concedidas por tres IImos. Srs. Arzobispos y obispos año 1754 por gracia de Alonso Tello". En el grabado aparece la Virgen, mirando al frente, vestida con la misma indumentaria que tiene en la pintura que estamos analizando y donde se aprecian también las ráfagas de puntas de plata de martillo redondeadas, regaladas en 1733 por el citado canónigo, Alonso Tello de Eslava de la catedral de Sevilla.

El "Simpecado viejo" se sustituye a partir de 1766 cuando Don Bernardo María del Rocío Lasso de la Vega, perteneciente al Santo Oficio y alcalde de la Hdad. de Villamanrique, dona un nuevo Simpecado de plata repujada y artísticamente labrada y es el que actualmente recibe culto en la parroquia y sigue peregrinando a la aldea del Rocío.

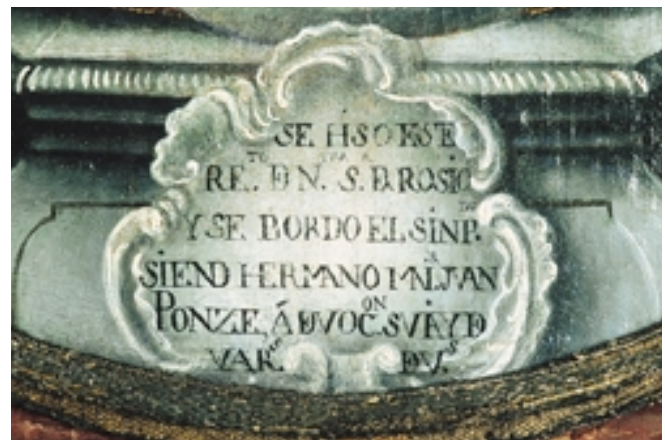

$\frac{\nwarrow}{\infty}$

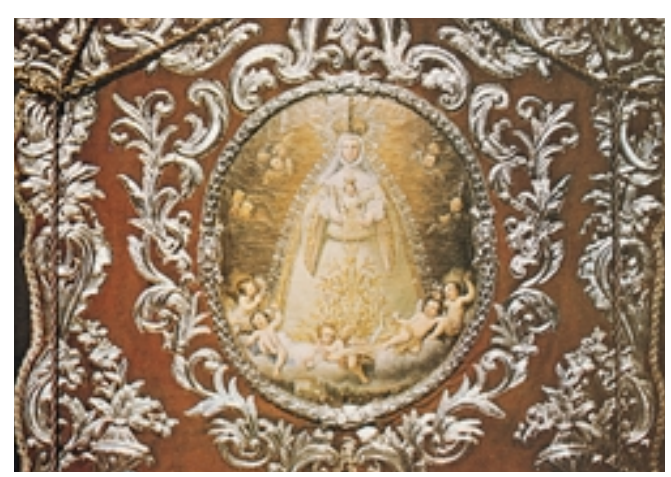

Cartela con rocallas con inscripción en la parte inferior de la pintura

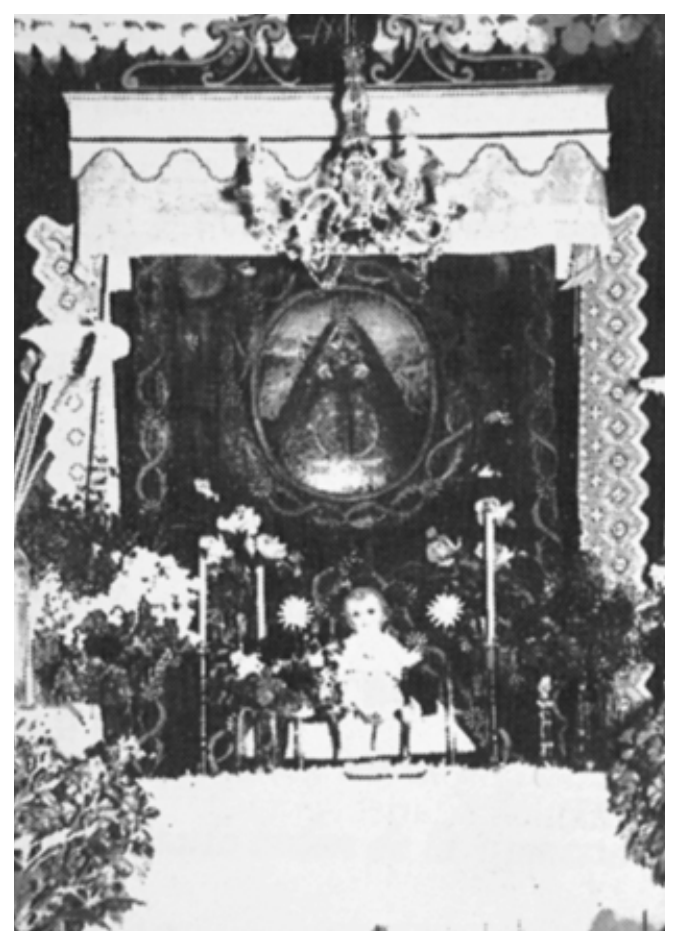

Detalle del denominado Simpecado Nuevo de 1766

Simpecado Viejo en la casa de un Hermano Mayor antes de 1972, en la denominada "la sala"
Por último, al analizar los distintos pigmentos que constituyen la pintura del óvalo central, donde se representa a la Virgen, detectamos en los azules por medio de la técnica de espectrometría infrarroja por transformada de Fourier, la presencia del pigmento llamado azul de Prusia (ferrocianuro férrico) material que se fabrica o inventa en Berlín por el alemán Diesbach en 1704 y que se empieza a comercializar desde el norte de Europa desde 1721. Los primeros datos que tenemos de la utilización de este pigmento en Andalucía en obras de arte, se deben al pintor sevillano Domingo Martínez que hacia 1735-1740, lo 


\section{$\frac{1}{\infty}$
$\vdots$
$\sum$
$\Sigma$}

Representación del Sol, elemento alusivo a la Concepción Inmaculada de María

Cartela bordada en diagonal con anagramas del Ave María surmontado por corona ducal
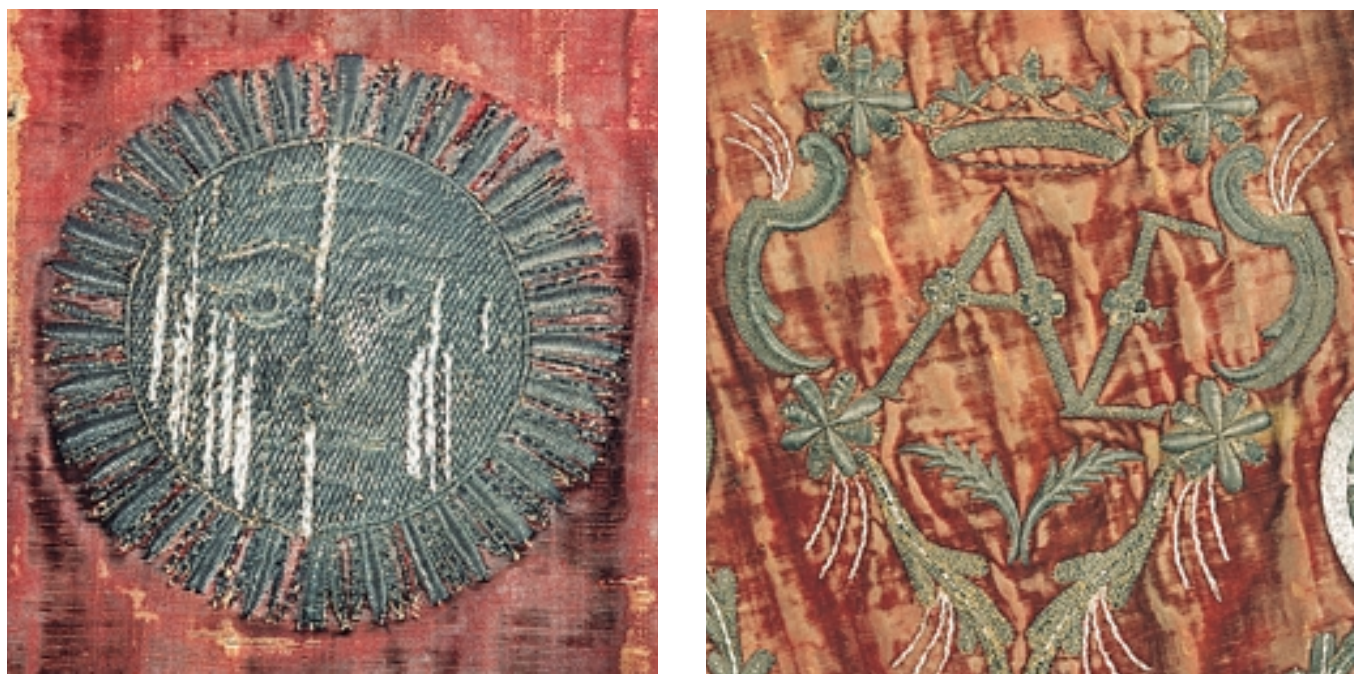

utiliza en el cuadro procedente del convento de San Francisco de Sevilla "La Apoteosis de la Inmaculada", que con la desamortización pasó a propiedad del Museo de Bellas Artes de Sevilla donde hoy se conserva 9 .

Con toda seguridad esta insignia mariana, se creó para peregrinar a la aldea del Rocío y recibir culto en otras celebraciones litúrgicas de la Hermandad, que probablemente se efectuaran en un principio en la antigua parroquia y en el vecino convento de Sta. María de Gracia, de la orden franciscana, desaparecido a mediados de este siglo.

Desde tiempo inmemorial se creó la tradición de darle culto al "Simpecado viejo" en la casa del Hno. Mayor de la romería de cada año, donde se adornaba o preparaba la denominada "sala" o mejor habitación del hogar que se adornaba con flores, macetas, encajes, etc., y que era destinada a una especie de capilla provisional. Hasta 1972 esta tradición se mantuvo, pues en ese año se adquiere por la Hermandad la antigua ermita de Santiago, convirtiéndose este recinto en la actual Casa Hermandad o Capilla del Rocío de Villamanrique y colocándose esta antigua insignia en la carreta vieja de madera para que pueda ser contemplada por sus devotos a través de una ventana 10.

Actualmente se le ha realizado una vitrina que asegure su estado de conservación y será instalada en el nuevo museo comarcal de Villamanrique.

A lo largo de su historia material esta obra ha sufrido varias restauraciones, con pequeños añadidos que no han alterado su morfología excesivamente, conservando su forma original, tanto en la pintura como lo que es el tejido y bordado. Aunque no documentadas sí se han apreciado durante el proceso de intervención en el I.A.P.H. anteriores restauraciones en el lienzo y en el tejido, siendo únicamente documentada la que se llevó a cabo en 1979 y que afectó principalmente a los bordados de plata. Encontrándose en su interior, es decir, en la tela de al- godón de refuerzo entre el terciopelo y el forro dos inscripciones repetidas en letra mayúscula y tinta industrial con la siguiente frase:"Se hizo en 1480 siendo Hno. Mayor Juan Ponce de León, se restauró en 1979 por el Hno. Mayor Juan Márquez Fernández y fue su restauradora María Angeles Espinar Díaz". Estas inscripciones se encontraban situadas una detrás de la pintura y la otra en el ángulo inferior izquierdo del Simpecado.

La morfología que presenta este "antiguo o viejo Simpecado" de la Virgen del Rocío de la Hermandad. de Villamanrique, consiste en un asta o vara de metal en vertical, de gran tamaño rematada por una cruz y un travesaño horizontal al pie de ésta, del que cuelga por medio de una serie de presillas añadidas, un gran paño rectangular de terciopelo de seda rojo bordado en plata con algunos apliques decorativos. Esta pieza posee una abertura triangular en su tercio inferior para que pueda ver la persona que lo porta.

En su centro se representa por mediación de un óvalo una pintura sobre lienzo de la imagen de la plata a manera de marco un galón realizado en técnica de setillos. A su vez este galón está rodeado por una greca o guardilla constituida por flores y tallos entrelazados y técnicamente realizado por diversas tipologías de puntos de bordados, fundamentalmente, setillos, cartulinas, hojillas, ajedrezados y oro llano.

En los ángulos superiores de este Simpecado aparecen representados el Sol y la Luna elementos claramente alusivos a la Concepción Inmaculada de María y realizados igualmente en técnica de setillos y con detalles de hilos de torzal redondos. Hacia abajo en ambos lados del centro se encuentran sendas cartelas en diagonal, constituidas por especie de rocallas y tallos junto a flores de ocho pétalos que circundan anagramas del Ave María surmontado por coronas ducales (con ocho florones) y debajo palmas encontradas. Todo el contorno de la obra presenta una elegante greca o guardilla con los mismos motivos ornamentaVirgen del Rocío, alrededor de la cual se borda en 
les que la que circundan el óvalo central, es decir, tallos y flores entrelazadas. Además en todo su perímetro más exterior aparece un fino cordoncillo que lo perfila y le da un aspecto de terminación y fineza. Como complementos en los extremos inferiores llevaba unas pequeñas campanillas en metal plateado y alrededor del Simpecado un grueso cordón que se anudaba al asta y al travesaño, para caer por ambos lados, teniendo dos jarras en pasamanería en su centro de hilos de seda y acabando este cordón en borlones con flecos.

La pintura representa en su centro la imagen de la Virgen del Rocío, con mirada al frente y paisaje al fondo donde se aprecian la antigua ermita con tejado a dos aguas y pequeña espadaña, carretas sin lonas, abrevadero y personajes vestidos a la usanza de la época.

La Virgen aparece adornada con indumentaria de gran dama, con jubón tieso, falda de configuración cónica, llamada basquiña muy acampanada. Esta prenda de finales del siglo XVI o principios del XVII se transforma en más ancha en el siglo XVIII. Su talle es alto, apretado y ampuloso con mangas perdidas y puños de encaje. El corpiño ajustado y ricamente adornado por bordados a la manera antigua y su gorguera blanca fue evolucionando, en el caso de la Virgen del Rocío, hasta convertirse en una especie de cofia o tocado que envolvía totalmente el rostro culminando en una especie de rostrillo. También en la pintura se aprecia un bordado, sobre todo en la basquiña, con gran espacio vertical o eje central repleto de bordados con rocallas que se desarrollan en oro por la base, dejando el resto del vestido sin bordar pero con una decoración floral propia del barroco tardío o rococó.

Así aparece también en el grabado de la Virgen que mandó hacer Alonso Tello de Eslava en 1754, donde luce un traje que precisamente le regaló en 1733 junto con unas ráfagas este canónigo de Sevilla y Don Miguel Alonso Carrillo deán de dicha catedral. Que no tiene nada que ver con el vestido de la pintura del Simpecado nuevo de 1766.

Iconográficamente en esta pintura aparece la Virgen del Rocío como una variante de la Virgen Majestad o "Kyriotissa", modelo muy utilizado en Bizancio durante la Edad Media. Se representa a la Madre de Dios como la mujer apocalíptica en pie sobre la luna rígida y mayestática, rodeada de ráfagas o mandorlas y coronada por estrellas, que ofrece a su Hijo sostenido por Ella ante su pecho. El profesor Hernández Díaz incluye a la Virgen del Rocío en un tipo de iconografía mariana llamada por él Virgen del Magnificat por su relación con el cántico del mismo nombre cargado de esencias teológicas a la vez que humanas. De esta forma son representaciones profundas de conceptos pero con gracia y galanura en su narrativa 'I.

Los atributos que porta la Virgen derivan de dos simbologías distintas: del tema de la Inmaculada Con-

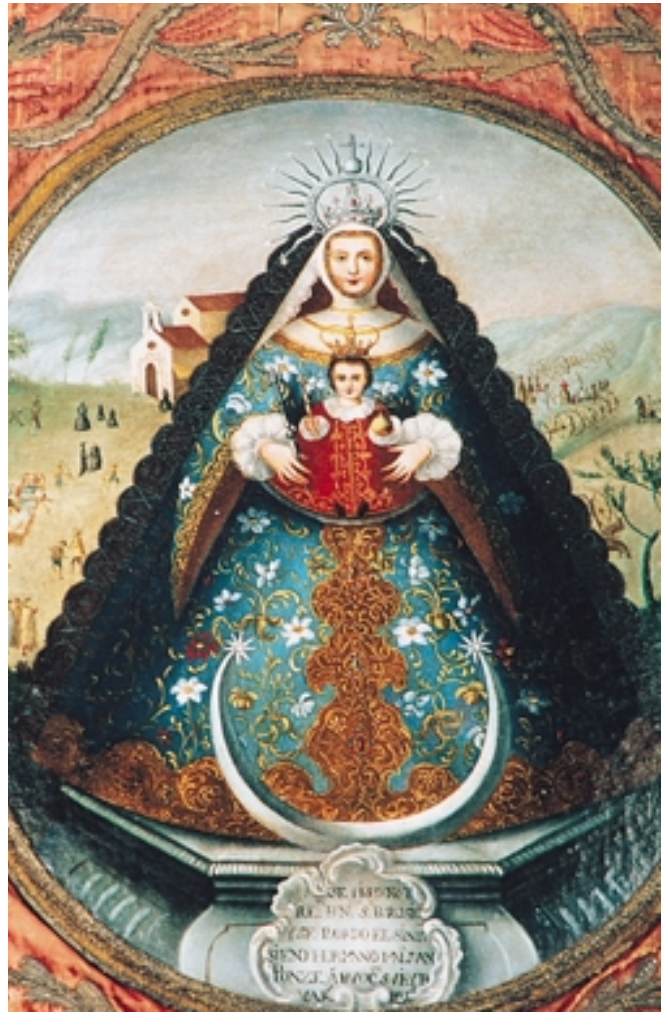

$\frac{\pi}{\frac{\pi}{0}}$

Óvalo pictórico donde aparece la Virgen vestida a la usanza de una gran dama de la época

Simpecado de la V. de Rocío de la Hermandad de Pilas

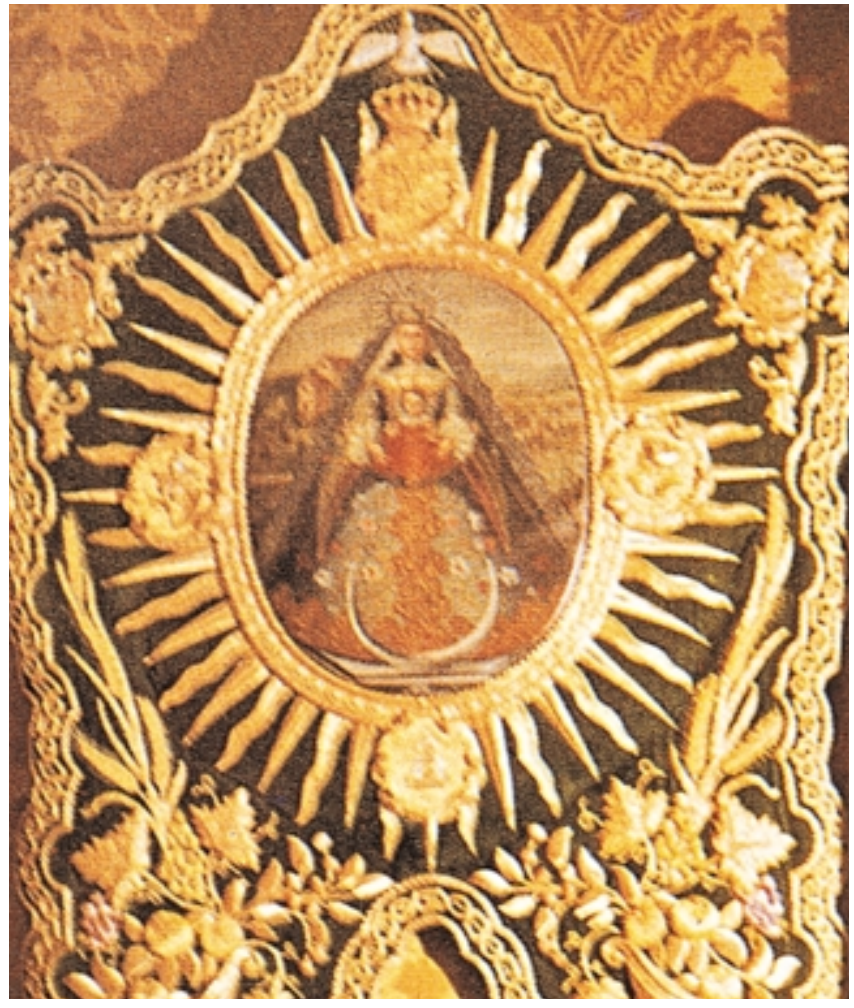

cepción y del poder de su Hijo Jesucristo. Del Apocalipsis de san Juan en su capítulo 12, versículo I, deriva la representación de la Inmaculada: "En esto apareció un gran prodigio en el cielo, una mujer vestida de sol y la luna debajo de sus pies y en la cabeza corona de dos estrellas". En el óvalo presenta estos tres atributos, está vestida de sol por las ráfagas de destellos, aparece coronada como reina de los cielos 
y a sus pies posee los cuernos de la luna rematados por dos estrellas. Los atributos de poder se encuentran en la figura del Niño como verdadero Rey del universo con cetro, corona y esfera terráquea coronada por la cruz (los dos primeros atributos son compartidos por María).

Tanto la corona como el cetro de influencia cortesana con moharra o terminación en forma de flor de lis puede simbolizar la casa de Aragón o la nueva dinastía borbónica de principios del siglo XVIII. Estos símbolos de poder efectivo sintonizan con la posición hierática y frontal de María y Jesús que se pueden considerar como un nuevo elemento que expresa poder. Además el Niño aparece con los atributos de oro mientras que la Virgen los sostiene de plata 12.

También hay que decir que este "antiguo o viejo Simpecado" ha servido de inspiración y modelo para la confección de otros Simpecados. Como el que existe en las dependencias de la parroquia de Santa María Magdalena de Villamanrique, dedicado a la advocación de la Virgen del Rosario que se representa en un círculo o tondo en su zona central, sentada en un risco y flanqueada por dos ovejas por lo que popularmente se le llama "La Pastora". La pintura de gran calidad y próxima a un seguidor de Murillo, la podemos situar en la primera mitad del siglo XVIII, al igual que los bordados de aplique de raso blanco de seda perfilados en plata que siguen muy de cerca la misma composición y motivos decorativos que el Simpecado que hemos intervenido.

También la pintura del óvalo central de este "Simpecado viejo" de la Hermandad de Villamanrique, fue el modelo a seguir para el Simpecado que peregrina actualmente al Rocío de la Hermandad de Pilas, confeccionado por Esperanza Elena Caro en el año 1977.

Así mismo, la Hermandad de Villamanrique posee dos Simpecados además del antiguo y nuevo de 1766 . El realizado en 1986-1987 a imitación de este último que normalmente se encuentra en la casa de la Hermandad de la aldea del Rocío, confeccionado en terciopelo rojo y grandes apliques de plata y una copia muy libre de la pintura del "Simpecado viejo" diseñada por Juan Márquez. Y el estrenado el 8 de mayo de 1999, para cumplir las funciones que desempeñaba el restaurado en el I.A.P.H., bordado por Benjamín Pérez, de Bollullos de la Mitación, siguiendo el diseño de este último, confeccionado en terciopelo burdeos de Lyon y bordado en plata, teniendo en el centro una pintura de Juan Luis Aguado.

Lo que demuestra que esta obra que ha sido restaurada tiene un valor excepcional porque ha servido de inspiración de casi todos los Simpecados que actualmente peregrinan a la aldea del Rocío.

En conclusión podemos decir que el "viejo o antiguo Simpecado" de la Virgen del Rocío de la Hermandad de Villamanrique de la Condesa es una elegante obra de autoría anónima y modelo a seguir por las demás hermandades y realizada hacia los años 1733 y 1750.

En primer lugar porque todos los documentos consultados coinciden aproximadamente con esta primera mitad del siglo XVIII, incluida la inscripción de la cartela de la pintura que hace referencia a Juan Ponze como Hno. Mayor entre los años 1725-1735. Y además porque el nuevo Simpecado se estrenó en 1766.

En segundo lugar por tener la pintura del óvalo central entre sus pigmentos azul de Prusia, material utilizado en Andalucía a partir de 1735- 1740.

Y, por último, por su comparación estilística y morfológica tanto en la pintura donde aparecen características propias de un barroco tardío, con ornamentación de rocallas, como en el tejido bordado de corte muy dieciochesco de finos tallos y pequeña floración entrelazada además de composición muy delimitada.

\section{Notas bibliográficas}

I. Libro de la Montería que mandó escrevir el Muy Alto y Muy Poderoso Rey Don Alonso de Castilla, último de este nombre. Acrecentado por Argote de Molina, Gonzalo. SeviIla, 1582 .

2. A.A.V.V. El Rocío, fe, y alegría de un pueblo. Tomo II. Granada, 1981, págs. 65 y 66.

3. Archivo Parroquial de Villamanrique. (A.P.V.) Libros I, II de Defunciones a partir de 1708.

4. A.P.V. Libros de Bautismos a partir del siglo XVIII.

5. Carrasco Díaz, Manuel. Historiando el Rocío. Sevilla, 1970. pág. 18.

6. Op. cit pát. págs. 16 y 23.

7. Op. cit. pág. 24

8. Op, cit. pág. 17

9. González López, Ma. José. Tesis Doctoral. Estudio de las preparaciones de pintura sobre soporte de tela y tabla. Caracterización de sus principales componentes, comportamiento y factores de deterioro. Sevilla, 1992. pág. 598.

10. Boletín Informativo. Hdad. del Rocío de Villamanrique de la Condesa. N², mayo, 1998. pág. 17.

I I. Hernández Díaz, José. La iconografía mariana en las tierras del antiguo reino de Sevilla. Sevilla, 1980.

I2. A.A.V.V. El Rocío, fe y alegría de un pueblo. Tomo II. Granada, 1981, págs. 236, 237, 238. 


\section{OBRA PICTÓRICA}

\section{Datos técnicos}

La obra pictórica está realizada al óleo sobre un soporte mixto. Este soporte se compone de un lienzo sobre el que se ejecuta la pintura, adherido por su reverso a una madera. La madera a su vez está pegada al terciopelo base del simpecado. Un galón realizado con hilos metálicos rodea la pintura ocultando los bordes del lienzo pictórico.

Para confirmar este tipo de montaje, durante el proceso de intervención se descosió una pequeña parte del galón que rodea la pintura. De esta manera, se pudo acceder al borde del soporte pictórico, comprobándose que bajo el lienzo aparece una madera de poco grosor. Esta madera presenta una suave curvatura intencionada de tipo convexa. A parte de estar pegada al terciopelo presenta unas puntadas de un hilo grueso que atraviesan la madera, el terciopelo y el tejido de lino bajo éste que sirve de refuerzo para los bordados.

Estas puntadas se localizan en el perímetro y en la parte vertical central del soporte lígneo.

La parte vista de la pintura mide $53,8 \mathrm{~cm}$ en su eje vertical y $42,5 \mathrm{~cm}$ en su eje horizontal. Esta medida coincide con las del soporte de madera pues éste no alcanza los bordes del lienzo que quedan ocultos por el galón perimetral.

Estos bordes de la tela pictórica, donde la madera no está presente, están pegados al terciopelo y tiene a su vez puntadas de hilo a intervalos irregulares que cosen el borde del lienzo con el terciopelo. El adhesivo utilizado para unir el lienzo a la madera es gacha, confirmado por la analítica realizada.

El tejido constituyente del soporte pictórico es de lino. El material constitutivo del soporte lígneo es madera de pino.

Sobre el lienzo utilizado como soporte se aplica una capa de preparación o imprimación anaranjada sobre la cual se ejecuta el estrato de color. La capa pictórica está elaborada a base de colores cubrientes con pequeños puntos de relieve de color blanco y ocre claro localizados en los vestidos para representar los bordados y en las joyas. Con trazos rápidos y pincelada segura configuran las pequeñas figuras y paisaje del fondo. El paisaje contrasta en luminosidad con la figura de la Virgen.

Se analizaron los principales pigmentos del estrato de color extrayendo pequeñas muestras principalmente de los bordes ocultos por el galón.

La identificación del pigmento azul ha sido un dato clave para confirmar que esta pintura se realizó sobre el primer tercio del siglo XVIII. Al descartar tras los estudios analíticos, que el pigmento fuese un azul inorgánico de los utilizados en épocas anteriores (lapislázuli, azurita...), se realizaron otras pruebas para ver si se trataba de un pigmento orgánico tradicional

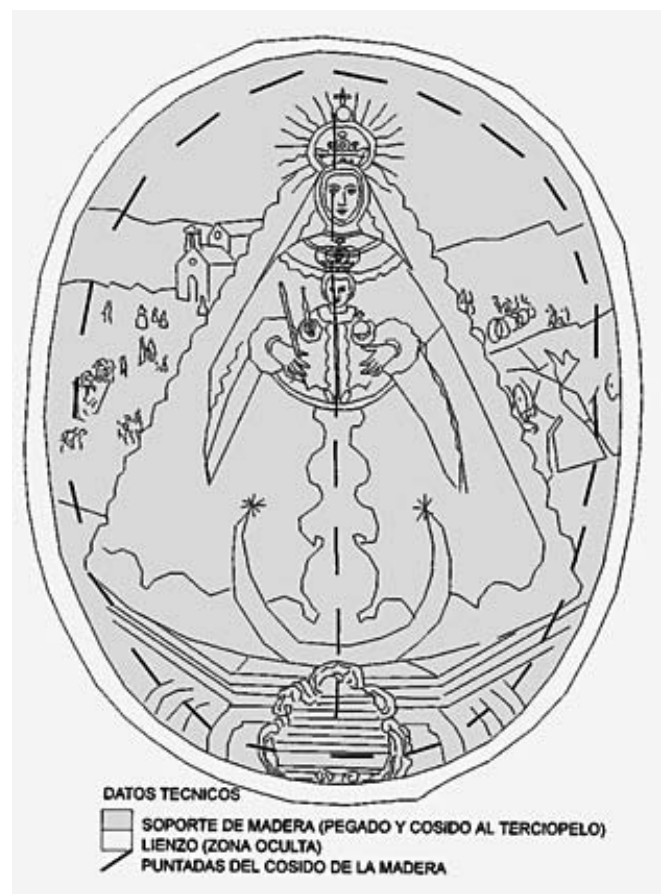

como el azul índigo. Tras los resultados negativos se confirmó por último que se trataba de azul de prusia, un pigmento inorgánico de síntesis industrial.

\section{Estado de conservación}

Tras el conocimiento de los datos técnicos más importantes se llevó a cabo el estudio sobre el estado de conservación que presentaba la obra a su llegada al IAPH. La aplicación de una metodología de trabajo establecida nos ha permitido definir los estudios preliminares necesarios para formular un diagnóstico y un proyecto de actuación sobre el bien, garantizando así su intervención.

Partiendo de la base de que cualquier intervención debe ir precedida de un análisis sobre los materiales y técnicas constitutivas, los factores de deterioro y degradación y las patologías presentes se realizan una serie de estudios y análisis físico - químicos que nos llevan a conocer en profundidad la obra.

Dentro de los métodos físicos de examen se realizó un estudio radiográfico aportando información no visible al ojo humano sobre la estructura interna y externa de la obra. Un examen con iluminación ultravioleta nos informaba sobre la repartición y acumulaciones de la capa de barniz así como de la presencia de repintes. Estudiando la superficie con luz rasante se apreciaban claramente las deformaciones ondulatorias del soporte textil. Un seguimiento fotográfico sobre datos de interés del antes, durante y después de la intervención completan este estudio.

El estudio analítico sobre los materiales constitutivos y la técnica de ejecución han sido útiles para el conocimiento histórico-artístico y su estado de conservación identificándose los materiales originales y añadidos. 


\section{$\frac{1}{\infty}$
$\frac{1}{\Sigma}$
$\Sigma$}

Estudio con luz rasante donde se aprecian los levantamientos del lienzo pictórico

Fase de eliminación de barnices oxidados
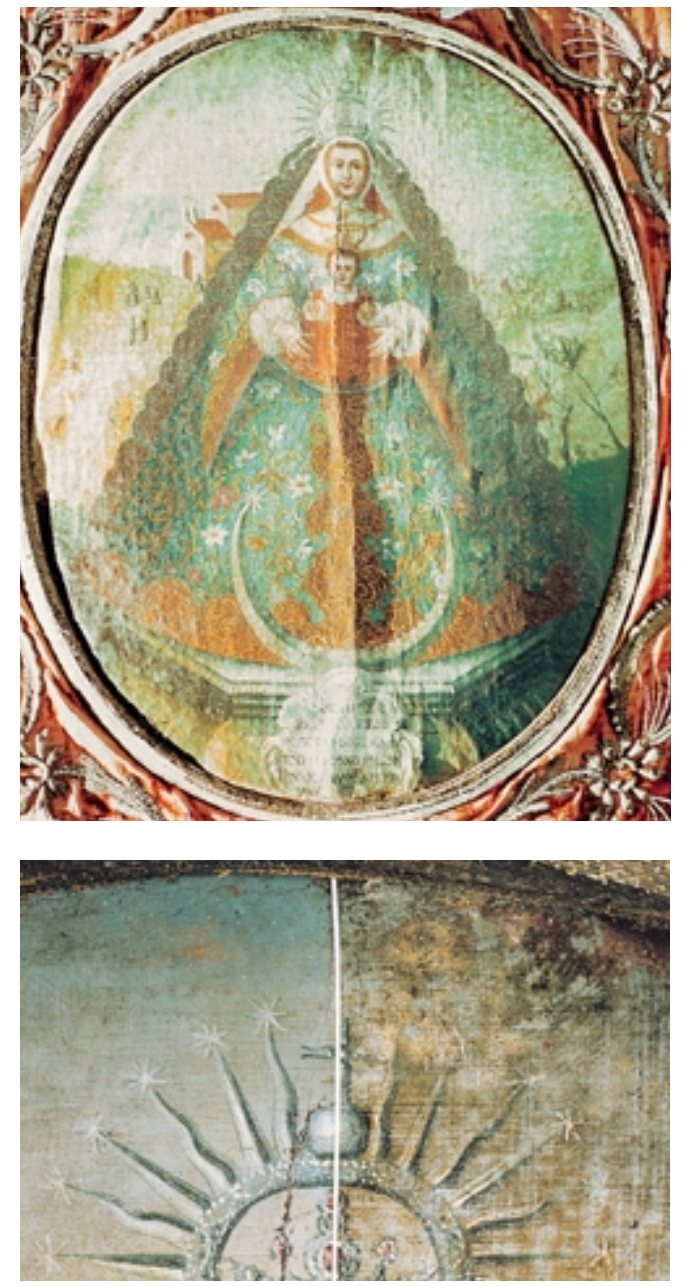

\section{Alteraciones}

Los factores de degradación causados por agentes externos o internos de la propia obra como son las tensiones provocadas por el movimiento natural de dilatación y contracción de la madera y el lienzo han dado lugar a una serie de alteraciones entre las que destacan los abolsamientos originados por la separación del lienzo pictórico con el soporte de madera reflejándose en pliegues pronunciados. Se localizan principalmente en la zona central vertical. Otros pliegues de menor tamaño se localizan igualmente en sentido vertical en la mitad derecha del lienzo; en la zona inferior, en sentido horizontal bajo la inscripción y en el lateral izquierdo en la zona superior

Otra de las alteraciones presentes es la pérdida de pintura y estrato de preparación en forma de pequeñas lagunas muy localizadas que coinciden con las zonas de pliegues fundamentalmente en la zona central afectando a los rostros de la Virgen y fundamentalmente al del Niño.

En los bordes del lienzo ocultos por el galón, confirmado por el examen radiográfico, el estrato de preparación y la película de color presentaba zonas pulverulentas con falta de adhesión y pequeñas pérdidas debido principalmente al conjunto de puntadas reali- zadas para unir el hilo plateado añadido del galón con el terciopelo.

A parte de los levantamientos citados anteriormente, que habían causado la pérdida de pintura hay que decir que el lienzo se encontraba perfectamente adherido a la madera. Al imposibilitarse el acceso al soporte de madera se desconocía si existían otro tipo de alteraciones. Con este propósito se realizó una radiografía pues se tenía la sospecha que la madera pudiera presentar roturas, grietas o ataque de insectos xilófagos. Este estudio nos confirmó el buen estado de conservación que presentaba este soporte apreciándose tan sólo la zona agrietada de la pintura y dos lagunas estucadas en la zona inferior de la saya de la Virgen.

La oxidación del barniz y la suciedad superficial daban un oscurecimiento general a la película de color. Extendido por toda la superficie presentaba acumulaciones en forma de pequeñas manchas

En esta pintura se aprecia una granulosidad superficial muy tenue debida a los grumos del adhesivo utilizado para unir el lienzo con la madera. El barniz, por ello, se ha acumulado en la zona inferior de estas irregularidades mostrando ese aspecto desigual.

\section{Intervenciones anteriores}

En este apartado destaca una limpieza agresiva que se realizó sobre la película pictórica provocando desgastes irreversibles del color, principalmente sobre las figuras del paisaje y sobre la inscripción de la peana. Otra de las intervenciones realizadas fue el estucado de dos pequeñas lagunas de color localizadas en la media luna a los pies de la Virgen.

Hay que tener en cuenta la funcionalidad de este tipo de obra para comprender el estado de conservación que presentaba. Este simpecado, que durante algún tiempo se llevó en peregrinación soportó cambios bruscos de humedad, temperatura e iluminación así como acumulación de suciedad. Otro de los factores que ha acrecentado su degradación era el conjunto de vibraciones, movimientos y roces que sufría el soporte pictórico con el varal durante su recorrido. Hay que destacar igualmente, que durante aproximadamente dos siglos, cada año por lo general el simpecado permanecía en la casa del que entonces fuese hermano mayor. Todo ello ha originado graves daños no intencionados causados por la variación de temperaturas de unas casas a otras, humedad variable, tipo de iluminación, manipulación, velas, etcétera.

\section{ESTUDIO ANALÍTICO}

\section{Análisis estratigráfico}

Se tomaron un total de ocho muestras: siete de pintura y una de fibra del lienzo. Los fragmentos de pintura se englobaron en metacrilato y se cortaron perpendicularmente para obtener la sección transversal. En es- 
tas secciones se analizaron tanto la capa de preparación como las de pintura. En cuanto a el tejido, se realizó la preparación, tanto de la sección transversal como la longitudinal, para la identificación de las fibras textiles.

La metodología de trabajo seguida fue la siguiente:

- Examen preliminar con el microscopio estereoscópico de los fragmentos de pintura extraídos y preparación de la sección transversal o estratigrafía.

- Observación al microscopio óptico con luz reflejada de la sección transversal.

- Estudio al microscopio electrónico de barrido y microanálisis elemental mediante energía dispersiva de rayos $X(E D A X)$ de la sección transversal.

La metodología seguida en el estudio de las fibras del soporte es descrita en el apartado de identificación de fibras textiles e hilos metálicos.

La pintura presenta una imprimación coloreada compuesta por blanco de plomo, calcita y tierra roja. Su espesor oscila entre 200 y $315 \mu \mathrm{m}$.

El tejido constituyente del soporte pictórico es de lino.

Los distintos colores de la capa pictórica tienen la siguiente composición:

- Los blancos son de blanco de plomo.

- Los rojos están compuestos por bermellón, blanco de plomo y trazas de tierra roja. Superpuesta a esta capa se observa una veladura de laca roja.

- Los azules están compuestos por blanco de plomo mezclado con un pigmento azul no identificado. La caracterización del mismo se realizó mediante espectroscopía de infrarrojos con transformada de Fourier (FT-IR).

- Los verdes están constituidos por blanco de plomo, el pigmento azul mencionado anteriormente, ocre y trazas de tierra roja.

En el estudio se han identificado los siguientes pigmentos:

Blancos: blanco de plomo (carbonato básico de plomo) y calcita (carbonato cálcico)

Rojos: tierra roja (silicatos arcillosos coloreados por óxidos de hierro), bermellón (sulfuro de mercurio) y laca roja (colorante orgánico fijado sobre una carga inerte, generalmente hidróxido de aluminio)

Amarillos: ocre (aluminosilicato coloreados por óxido de hierro hidratado)

\section{Análisis espectroscópico}

Mediante espectrometría infrarroja por transformada de Fourier, empleando el método de dispersión y prensado de muestras en una matriz de bromuro potásico, y utilizando un rango espectral de 4000 a 400 $\mathrm{cm}^{-1}$, se han analizado muestras correspondientes a distintos materiales: pigmento azul, adhesivo y barniz.

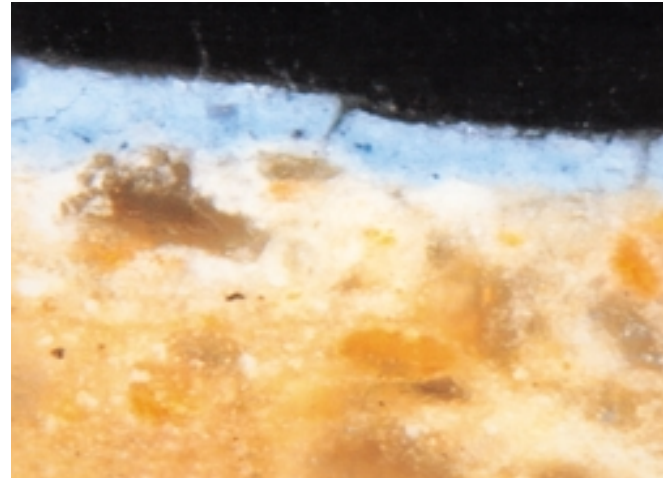

Gráfico 1. IDENTIFICACIÓN DEL PIGMENTO AZUL DE PRUSIA

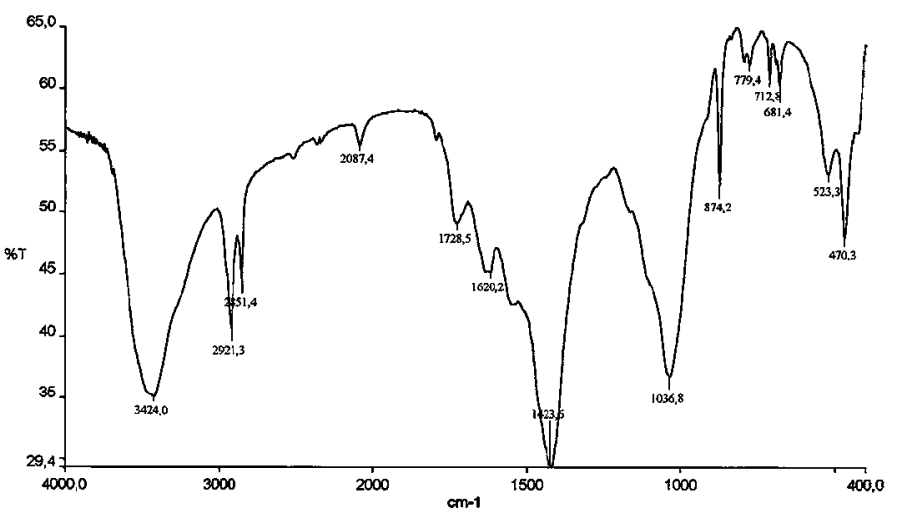

En la muestra de pigmento azul del manto se detecta la presencia de azul de Prusia (ferrocianuro férrico, $\left.\mathrm{Fe}_{4}\left[\mathrm{Fe}(\mathrm{CN})_{6}\right]_{3}\right)$ pigmento en uso desde el siglo XVIII.

En el barniz se detecta la presencia de goma laca, resina natural que se extrae del árbol Antea frondosa como secreción del insecto Coccus laca.

El adhesivo está constituido por gacha.

\section{Tratamiento}

Los criterios de intervención tomados en consideración una vez realizado el diagnóstico pormenorizado sobre el estado de conservación respondían a dos tipos de propuestas.

La primera era acometer su restauración independientemente del terciopelo bordado. Para ello sería necesario separar el galón formado por hilos metálicos que rodeaban la pintura con el riesgo que quedaran sueltos muchos de estos hilos. Por otra parte, si se separaba la madera del terciopelo sobre el cual estaba bien adherida podría destruirse parte de esta superficie textil. Es por ello, y tras sopesar los pros y contras de la actuación cuando se recurre a la segunda y definitiva propuesta de actuación. Ésta era intervenir sobre la pintura sin separarla del terciopelo que compone el simpecado.
Sección transversal de una muestra de pintura del azul del cielo, 200X 
$\frac{\frac{1}{0}}{0}$

Antes de la Intervención: Pérdidas en estratos pictóricos y barnices oxidados

Después de la Intervención
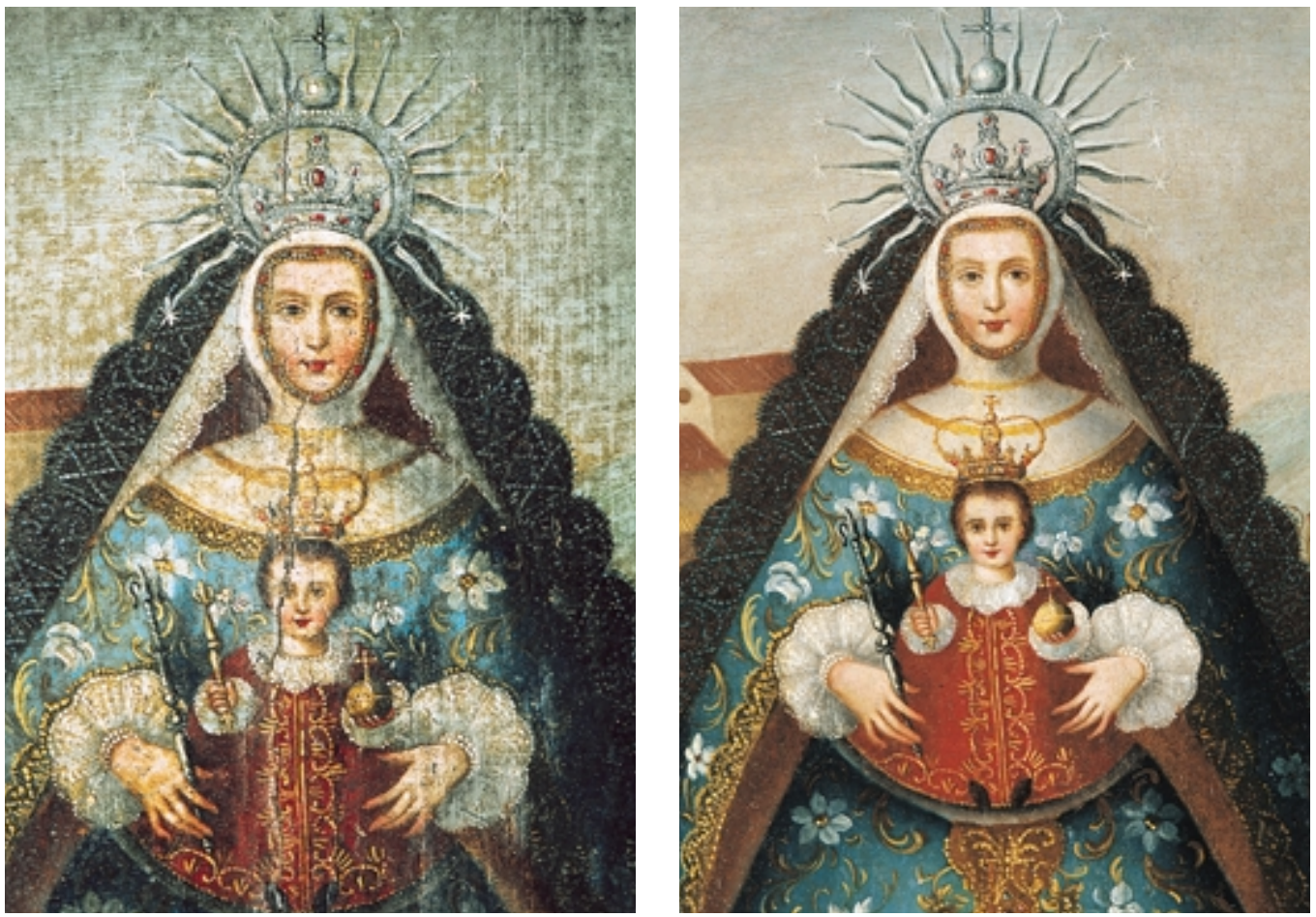
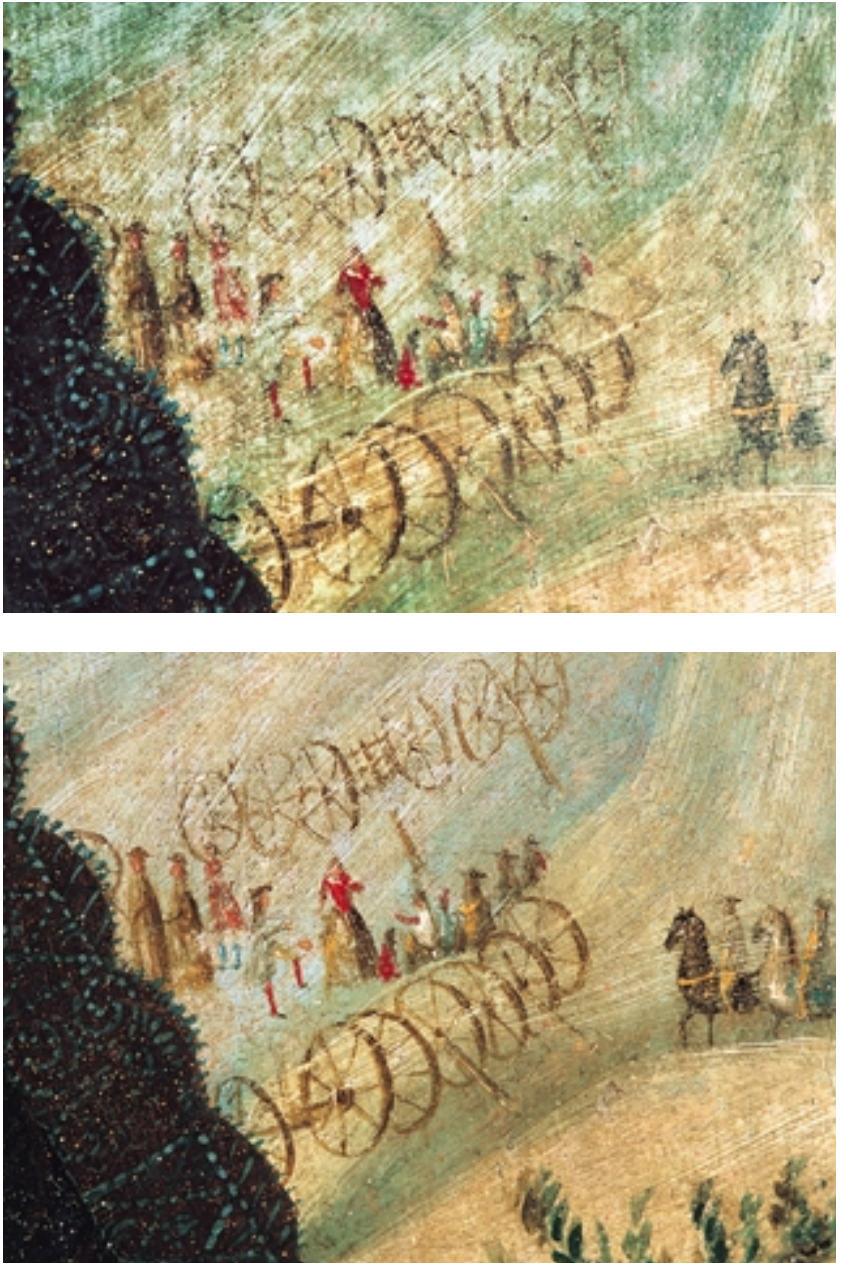

Antes de la Intervención: acumulación de barnices oxidados y desgastes de película pictórica

Después de la intervención
La primera operación realizada sobre la superficie pictórica fue la fijación de los levantamientos causados por la separación del lienzo con la madera. Para ello se cubrió la superficie a tratar con papel japonés utilizando como adhesivo coletta. Se procedió a bajar los pliegues con espátula caliente. El adhesivo se aplicó inyectando por zonas donde había pérdidas del estrato pictórico. Del mismo modo se realizó una fijación puntual sobre la película de color que presentaba falta de adhesión con el lienzo, fundamentalmente en los bordes perimetrales.

Una vez unido el lienzo al soporte lígneo se procedió a realizar una limpieza para eliminar los barnices oxidados y repintes localizados sobre los estucos.

Para determinar la elección del disolvente más adecuado se realizó un microtest de solubilidad. El desbarnizado se realizó gradualmente comenzando por el paisaje del fondo y finalizando con la figura de la Virgen con el Niño. Con la eliminación de la capa de barniz oscurecida y la suciedad superficial la superficie pictórica cobraba otro aspecto devolviendole la profundidad, cromatismo y volumen que había perdido.

Tras el desbarnizado y eliminación de los repintes y estucos que cubrían parte del original, se estucaron las lagunas de preparación con sulfato cálcico y cola animal. Seguidamente se reintegró cromáticamente la zona estucada siguiendo un criterio de reintegración invisible justificado por el tamaño de las lagunas. Se utilizó para ello una técnica acuosa, y tras un primer barnizado de la superficie, a brocha, se finalizó la reintegración del color con pigmentos al barniz. Como fase final se aplicó un barniz para protección de la superficie pictórica. 


\section{TEJIDO}

\section{Datos técnicos}

Los datos técnicos se determinaron en el taller de tejidos del IAPH tras el atento examen de la obra mediante inspección visual y en algunos casos con la ayuda de instrumentos de aumento como la lupa binocular. Así se ha podido determinar la descripción técnica de los tejidos y de la ornamentación empleada en su realización.

Terciopelo: El tejido base sobre el que descansan todos los elementos decorativos y bordados de la pieza corresponde a un terciopelo simple de pelo con un solo cuerpo, en materia de seda y de color rojo. Este terciopelo lo constituyen urdimbres de dos tipos: la urdimbre de fondo y la urdimbre de decoración que hace el efecto de pelo, ambas de color rojo. Sólo aparece un tipo de trama que es la que forma el tejido base del terciopelo en sus diferentes pasadas, en seda y de color crudo.

Los hilos de urdimbre de fondo están formados por múltiples cabos ligeramente torsionados en S. La densidad de estos hilos es de 90 hilos de urdimbre por $\mathrm{cm}^{2}$. La urdimbre de decoración presenta un número indefinido de fibras y torsión inapreciable con una densidad de 40 urdimbres por $\mathrm{cm}^{2}$. La densidad en total es de 130 hilos de urdimbre por $\mathrm{cm}^{2}$ entre hilos de urdimbre de fondo y urdimbre de pelo.

Los hilos de trama tienen una torsión en $S$ y están formados por un número indefinido de cabos. La densidad es de 44 hilos de trama por $\mathrm{cm}^{2}$.

En cuanto a la técnica de manufactura, la construcción interna del terciopelo se ha llevado a cabo en telares manuales. Las medidas generales del Simpecado son $194 \mathrm{~cm}$ de altura $\times 114,5 \mathrm{~cm}$ de ancho.

Tejido base: Bajo el terciopelo aparece un tejido de lino que sirve de refuerzo y base para la fijación de los motivos bordados. El ligamento es un tafetán simple que es más básico y el más antiguo del cual derivan todos los demás. La construcción interna del tafetán se limita a dos hilos y a dos pasadas, según lo cual los hilos pares y los impares alternan a cada pasada, por debajo y por encima de la trama.

Los hilos de urdimbre de color crudo, presentan un número de cabos indefinido pero numeroso, con torsión en Z. La densidad es de 14 hilos de urdimbre por $\mathrm{cm}^{2}$.

La trama también es de color crudo con torsión en Z y múltiples cabos. La densidad es de 12 hilos de trama por $\mathrm{cm}^{2}$

Bordados: En el caso de los bordados se han utilizado diferentes hilos metálicos con una aleación de oro y plata, que van fijados mediante hilos de seda de color amarillo. Estos motivos bordados se realizan directamente en la obra, cosiéndose a los dos estratos a la vez (terciopelo y lino). Es un tipo de bordado con el que se consigue un cierto realce. Todos estos hilos van dispuestos en la superficie del terciopelo sobre diferentes materiales de preparación o relleno y son los hilos de seda los que los van fijando siguiendo diferentes tipos de puntos. El galón que rodea a la pintura es el único elemento que se bordó aparte, teniendo además su soporte de lino independiente.

Los hilos metálicos empleados en la decoración corresponden a varias tipologías: muestra, camaraña, briscado u ondulado, hojillas, torzal redondo y cordoncillo. Los tipos de puntos utilizados son diversos: setillos, ajedrezados, cartulinas, hojillas y oro llano.

\section{Número de piezas constitutivas}

La obra en conjunto está formada por varias piezas: el Simpecado con pintura central, una vara o asta vertical con remate en cruz, el travesaño horizontal, unas campanillas de plata y unos cordones con jarras y borlones.

Las partes fundamentales que forman el cuerpo principal del Simpecado son: el terciopelo, el óvalo con la
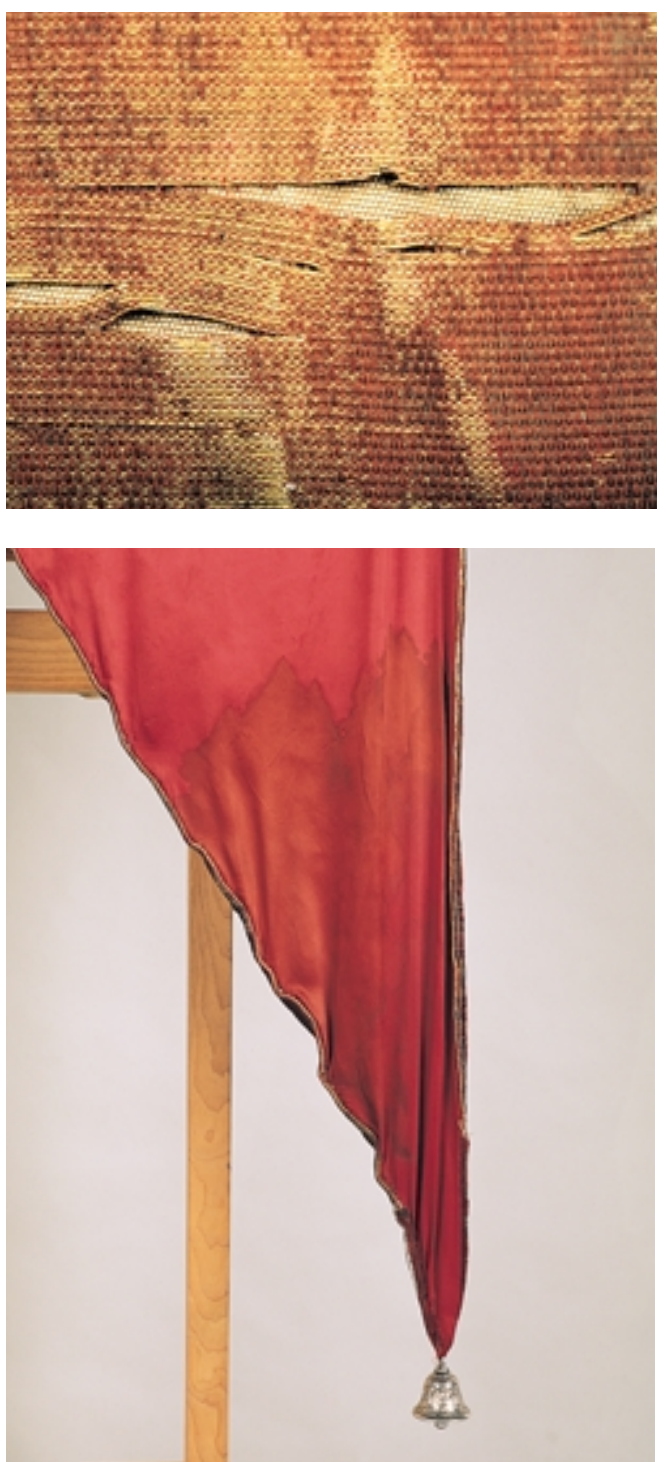

Detalle de la rotura del terciopelo

Detalle del reverso.

Mancha de humedad del forro 
$\frac{\pi}{0}$
$\frac{1}{\Sigma}$
$\Sigma$

pintura, los bordados, las presillas, una serie de estratos intermedios (tejido de lino original de refuerzo, tela blanca nueva y armazón interno) y el forro del reverso.

Los motivos bordados son: dos grecas o guardillas una perimetal y otra rodeando la pintura, dos cartelas inclinadas con anagramas, los símbolos del sol y la luna, el galón junto a la pintura, y un fino cordón por todo el borde exterior del terciopelo.

\section{Unión de las diferentes piezas constitutivas}

Se emplea para la unión de las tres piezas que constituyen el terciopelo un tipo de costura simple realizada con hilo de seda de color rosáceo. Las diferentes piezas que forman el soporte de lino bajo el terciopelo van unidas con hilo de lino mediante costura de unión viva en unas zonas y costura simple en otras.

Los estratos internos (tela blanca y armazón) así como las presillas están fijados con un tipo de hilo sintético grueso de color rojo. El forro que está formado por una sola pieza se une al resto con este mismo hilo rojo con punto de sobrehilado.

\section{Gráfico 2. CONSTRUCCIÓN INTERNA. TERCIOPELO SIMPLE}

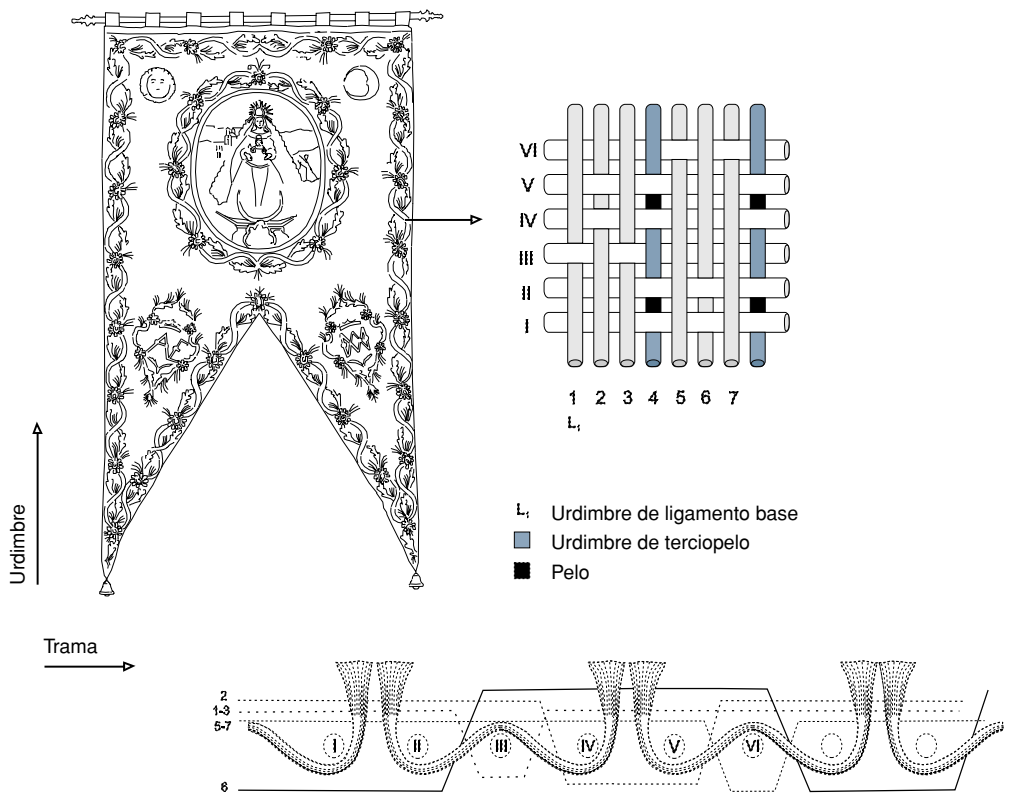

Todos los motivos bordados tienen un tipo de preparación o relleno excepto los que van con la técnica de oro llano. Los hilos metálicos van fijados al soporte mediante hilos de seda de color amarillo.

El galón que circunda a la pintura se bordó aparte, está fijado por sus bordes interno y externo con un hilo amarillo de seda que atraviesa los demás estratos (el borde interno: pintura, terciopelo y lino, y el externo sólo los dos últimos). También un hilo de cáñamo une internamente el galón a los estratos originales de terciopelo y lino.

\section{Estado de conservación}

\section{Alteraciones}

El Simpecado llegó a las instalaciones del IAPH en un deficiente estado de conservación presentando una serie de alteraciones que afectaban a la integridad física de la obra. Por este motivo la manipulación de la pieza se tenía que realizar con extremo cuidado. Hay que destacar entre las diferentes alteraciones las siguientes:

- Alto grado de fragilidad debido a agentes de deterioro externos a la obra: contaminación medio-ambiental, uso frecuente, manipulación inadecuada, prolongada exposición al sol, inadecuado sistema expositivo en vertical y bruscos cambios de temperatura y humedad. Además de todos estos factores también la fibra se había visto bastante dañada al haber sido sometida a un incorrecto y agresivo proceso de consolidación mediante el empleo de acetato de polivinilo. De este modo la degradación natural de la obra se había acelerado debido a los graves efectos negativos provocados por la aplicación del adhesivo.

- Las diferentes tensiones a las que se había sometido a la obra así como los roces y agresiones, habían creado lagunas de diferentes tipos: de hilos metálicos, de relleno de los bordados, de soporte de terciopelo y de soporte de lino bajo el terciopelo.

- Destacar la presencia de rotos y desgarros producidos fundamentalmente debido a la prolongada exposición en vertical de una obra que, además de presentar una evidente debilidad del tejido, tenía que soportar el peso de la pintura del tondo central que se encuentra montada sobre un soporte de madera.

Gráfico 3. Sección transversal

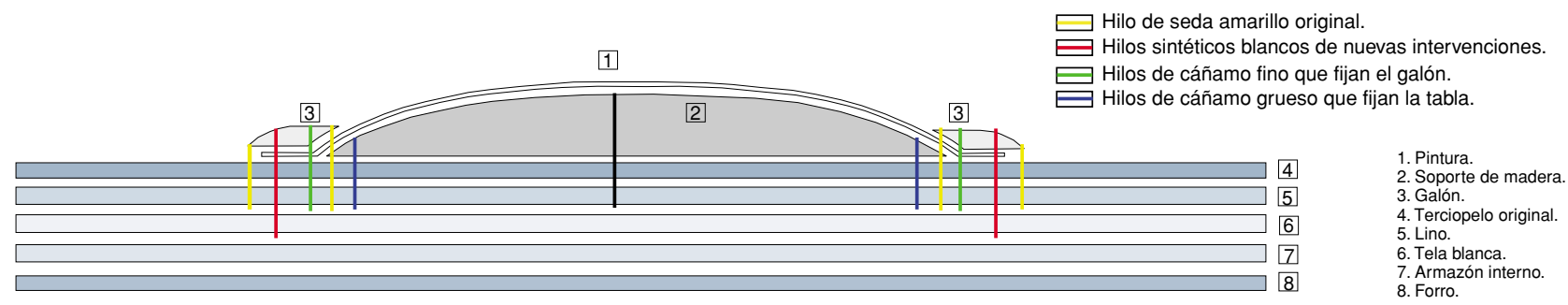


La mayoría de estos rotos eran horizontales y se concentraban en la zona superior.

- Los desgastes más evidentes de la obra eran los correspondientes a los del pelo del terciopelo y a los del bordado. Debido al uso de la pieza y a consecuencia de la construcción del terciopelo se había perdido parte del pelo, ya que queda en superficie y está más expuesto a los roces. El desgaste correspondiente a los bordados permitía ver el alma de seda de los hilos metálicos en los que la lámina exterior se había perdido, al igual que los hilos de seda que los mantenían fijados al soporte dando lugar a una serie de hilos sueltos.

- Se detectó también la presencia de alteraciones tanto de tipo microbiológico como biológico. El ataque microbiológico debido a la presencia de hongos y bacterias provocó graves daños en los tejidos afectados (seda, lino y algodón), que adquirieron un aspecto frágil y quebradizo. Este ataque se encontraba localizado en una de las esquinas inferiores, que se vio afectada en su momento por la presencia de humedad.

El ataque biológico en cambio había sido motivado por la acción de un roedor. Los restos de sus deyecciones se encontraron por el reverso de la obra junto a grandes lagunas en el tejido de lino, producto de su actividad. Eran lagunas muy bien definidas y con bordes limpios lo que indicaba que dichas pérdidas no se habían producido por enganches o por envejecimiento de la fibra.

- Se podían observar deformaciones en sentido vertical en toda la superficie de la obra a modo de pliegues. Entre las causas de esta alteración se encontraba la del incorrecto sistema expositivo anterior en vertical. También se habían deformado otras zonas del tejido creandose pliegues en horizontal, como la parte que está bajo la pintura debido al peso que tenía que soportar. El forro del reverso contribuía a deformar los tejidos originales haciendo que los bordes se ondularan. Las campanillas eran también la causa de algunas deformaciones en el forro por la tensión que ejercían debido a su peso.

- La alteración cromática de la pieza era evidente y correspondía a un tipo de pérdida gradual del color muy generalizada y repartida homogéneamente. Por la especial función para la que estaba destinada esta pieza hasta el momento de su intervención, se la sometía a prolongadas sesiones en las que incidía directamente la luz solar. Todo ello había contribuido a provocar o acelerar la decoloración de los tintes y colorantes empleados y a degradar la fibra de los soportes textiles.

Otro tipo de alteración cromática era la que se podía apreciar en zonas puntuales a modo de manchas, en las que el color del terciopelo se transformaba de rojo a amarillento. Posiblemente la causa de esta alteración era la aplicación de algún producto enérgico que se pudo emplear para la limpieza de los hilos metálicos de los bordados, junto a los que estaban localizadas estas manchas.
- Aparecían unas pequeñas separaciones en las costuras de las distintas piezas del terciopelo. Se producían debido a la pérdida o rotura del hilo rojo empleado para unirlas, o bien porque el tejido de las costuras se encontraba tan deteriorado que el hilo prácticamente no tenía soporte de sujeción.

- Se advertía en la obra la presencia de manchas que correspondían a diferentes tipologías: manchas de humedad en las que se apreciaban los cercos correspondientes a la migración de las tintas, manchas oscuras no identificadas que alteraban el color del terciopelo y manchas correspondientes al adhesivo empleado para adherir las diferentes intervenciones del reverso.

- Debido a los diferentes alfileres que se encontraban en el reverso en contacto con la tela de lino, se podían apreciar una serie de manchas de oxidación de la fibra como producto de la reacción química que había tenido lugar.

- La disgregación de la fibra era evidente debido a la gran suciedad y al envejecimiento natural de la misma, acentuado por el empleo del adhesivo. Así la fibra había perdido su consistencia y se deshacía llegando a ser irrecuperables sus características originales.

- Se apreciaban hilos metálicos sueltos que se encontraban repartidos indistintamente por toda la obra. Estos hilos al formar parte del estrato más superficial eran los que estaban más expuestos al rozamiento, rompiéndose los hilos de seda que los fijaban a la obra. Además este hilo de seda sufre un tipo de alteración natural que hace que con el tiempo se vuelva más frágil, perdiendo su consistencia.

- La suciedad era una alteración que de un modo generalizado presentaba esta pieza y que se podía apreciar fácilmente en una primera inspección visual. La gran acumulación de partículas en la fibra por el uso de la obra era tal, que alteraba de algún modo el color original de la misma.

\section{Depósitos superficiales}

En cuanto a los depósitos superficiales encontrados en la obra, destacar la presencia de restos de cera de abejas, así como gotas de cal en zonas puntuales del terciopelo.

\section{Intervenciones anteriores}

Las intervenciones encontradas en la obra alteraban su integridad física y modificaban la visión original de la misma, estando perfectamente localizadas en su mayoría. Hay que destacar la que tuvo lugar en el año 1979, la cual sometió a la obra a un agresivo proceso de consolidación mediante el empleo del adhesivo denominado acetato de polivinilo y se añadieron una serie de antiestéticos hilos plateados nuevos, que destacaban por su brillo más que los originales. 
$\frac{1}{0}$
0
$\Sigma$
$\Sigma$

Intervenciones anteriores de hilo metálico del bordado

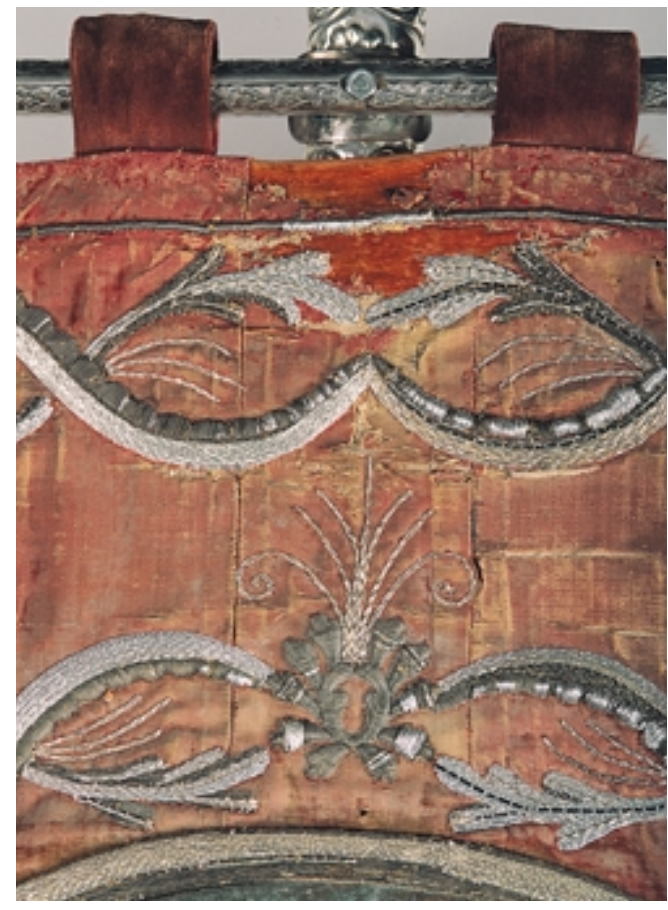

Las intervenciones identificables corresponden a:

- La aplicación de elementos nuevos como: el forro rojo de fibra artificial que cubría por completo el reverso de la pieza, las presillas también de fibra artificial de la zona superior para exponer la pieza en vertical, un armazón interno para reforzar el interior y que estaba compuesto por una estructura de hierro a la que se atornillaba una chapa de zinc y una tela blanca de algodón para fijar las intervenciones de hilo metálico.

- Parches que según su ubicación había que diferenciar entre los del reverso y del internos. Los del reverso eran aquellos que se adherían con cola al lino por su parte posterior. Estos en muchos casos montaban unos sobre otros, por lo que había que diferenciar varias capas o estratos (primer estrato de parches adheridos directamente al lino y segundo estrato de los que se adherían a otros parches). Por otro lado los parches internos eran los que aparecían pegados entre el terciopelo original y el lino del reverso. Para introducir estos elementos se tuvo que cortar el lino. Las diferentes materias utilizadas en estos añadidos eran tejido fino sintético de color rojo, terciopelo sintético rojo y tela blanca de algodón.

- Injertos de diferentes tipos. Dos reconstruían los ángulos inferiores en un tipo de tejido de fibra artificial celulósica. Otro que era de terciopelo nuevo y aparecía junto a la abertura inferior.

- Otro tipo de intervenciones eran las reconstrucciones parciales de la decoración correspondiente a hilos metálicos nuevos. Para cada motivo se empleaba un tipo determinado de punto, de hilo y de relleno. La fijación a los diferentes estratos (terciopelo, lino y tela blanca) se realizaba empleado hilos sintéticos de colores blanco y marrón a los que se había aplicado gran cantidad de cola. Los nuevos hilos empleados eran: hilo metálico plateado con alma de fibra artificial (tipo camarada), hilo metálico plateado con un matiz ligeramente más dorado con alma de algodón (tipo camarada) y hojilla metálica.

- Y por último los cosidos para reforzar las uniones de algunas partes. Variaba el grosor de los mismos según cada caso, siendo más fuertes que los que formaban el ligamento original de la pieza. En cuanto a la materialidad, estos hilos eran en unos casos sintéticos y otros de algodón.

Ha sido necesaria la eliminación de todas las intervenciones anteriores puesto que estaban dañando a la obra a la vez que presentaban un deficiente estado de conservación (lagunas, alteración cromática, rigidez, fragilidad, roturas, oxidación de la fibra, manchas, ataque microbiológico). El acetato de polivinilo es un material extraño y agresivo para los tejidos en general y por ello era fundamental eliminarlo de la obra en la medida de lo posible. Se degrada de una forma diferente a la de productos naturales como eran las fibras de esta pieza.También con la eliminación de los nuevos hilos metálicos, la lectura de la ornamentación sería más correcta pues eran éstos por su brillo los que adquirían más protagonismo que los originales. Además los hilos nuevos apenas poseían valor en cuanto a su materialidad, pues en un alto porcentaje no estaban compuestos por materiales nobles.

\section{Estudio analítico}

\section{Identificación de fibras textiles e hilos metálicos}

Se tomaron un total de veintitrés muestras: siete de hilos metálicos y quince de fibras textiles correspondientes tanto al tejido original como a diversas intervenciones posteriores o añadidos. También se analizaron dos fragmentos de tejido rojo: el primero fue encontrado en el reverso de un óvalo del que se sospechaba que podía tratarse de la pintura original y el segundo era un fragmento de un tejido rojo similar en apariencia al anterior y que había sido encontrado debajo del forro actual del simpecado.

La metodología de trabajo seguida para la identificación de las fibras textiles fue la siguiente:

- Estudio de la apariencia del tejido e hilos constituyentes al microscopio estereoscópico (lupa binocular) y al microscopio óptico con luz reflejada, a bajos aumentos.

- Estudio longitudinal de las fibras: una vez lavadas y separadas cuidadosamente, se observan al microscopio óptico con luz trasmitida polarizada estudiando su morfología, diámetro, agrupaciones, etc.

- Estudio transversal de las fibras: Para ello es necesario obtener previamente una sección perpendicular al sentido de las fibras, posteriormente se estudia dicha sección con la ayuda del microscopio óptico, con luz trasmitida, polarizada o no. 
- Estudio al microscopio electrónico de barrido (SEM) y microanálisis por dispersión de energía de rayos $X$ (EDAX) de los hilos metálicos para la identificación del metal de la cubierta.

Las fibras analizadas pertenecientes a los tejidos originales del SIMPECADO son las siguientes:

- Hilos metálicos: El hilo metálico plateado original es un entorchado de alma de seda, hilada en torsión S. La lámina metálica es una aleación de plata y oro. Asimismo el hilo metálico plateado en forma de hojilla también está constituido por una aleación de plata y oro.

- Fibras textiles: El terciopelo es de seda. El tejido situado debajo del terciopelo es de lino y está constituido por hilos con múltiples cabos y torsión S. El tejido base de los bordados originales y el hilo amarillo que fija el galón son también de seda mientras que el relleno del cordón perimetral es de cáñamo.

Los fibras encontradas en las distintas intervenciones son los siguientes:

- Hilos metálicos: se han encontrado tres tipos diferentes de hilos metálicos procedentes de intervenciones. El primero de ellos se trata de un hilo entorchado de alma de algodón, hilada en torsión Z. La lamina o cubierta metálica es una aleación cobre-plata. El segundo es, asimismo, un hilo entorchado aunque ahora el alma es de fibra sintética, hilada en torsión Z. La lámina externa no es metálica; se trata de un polímero clorado (plástico) con una fina película de aluminio recubriendo las dos caras. Por ultimo, el tercer caso se trata de un hilo metálico plateado en forma de hojilla cuya composición plata.

- Fibras textiles: Casi todos los tejidos encontrados son de fibras artificiales. En algunos casos se trata de fibras de celulosa regenerada y otras son fibras de polímeros sintéticos. También se han encontrado algunos hilos de algodón.

Otros tejidos analizados han dado los siguientes resultados:

El tejido rojo situado debajo del forro actual del simpecado es de seda. El tejido rojo adherido al reverso de la pintura supuestamente original es asimismo de seda.

\section{Identificación de colorantes naturales}

Se han analizado distintos fragmentos de fibras originales y de intervención al objeto de identificar posibles colorantes naturales. El análisis se ha realizado por cromatografía en capa fina, utilizando como fase estacionaria silicagel $60 F_{254}$ y como fase móvil: tolueno, formiato de etilo y ácido fórmico. Se han identificado los siguientes colorantes naturales:

\begin{tabular}{ll}
\hline Rojos: & Cochinilla y orchilla \\
\hline Amarillos: & Gualda \\
\hline Marrones: & Nogal \\
\hline Grises: & Agallas de roble y granado \\
\hline
\end{tabular}

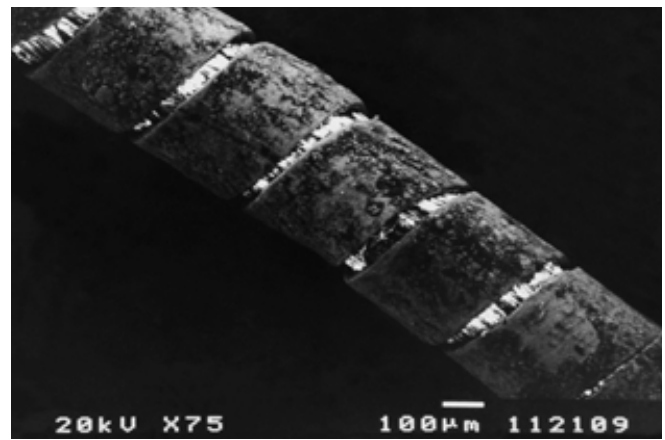

Cochinilla es un colorante rojo obtenido del insecto Dactylopius coccus, cuyo principal componente es el ácido carmínico.

Orchilla es otro colorante rojo obtenido de líquenes (Roccella tinctoria y otras especies) siendo el componente principal la orceína.

Gualda es un colorante amarillo obtenido de la planta Reseda luteola, constituido principalmente por luteolina.

Agallas de roble es un colorante negro grisáceo obtenido del insecto Cynips tinctoria y compuesto por galotaninos.

Granado es un colorante negro grisáceo obtenido de la planta Punica granatum y compuesto por flavogalol.

\section{Análisis espectroscópico}

Mediante espectrometría infrarroja por transformada de Fourier, empleando el método de dispersión y prensado de muestras en una matriz de bromuro potásico, y utilizando un rango espectral de 4000 a 400 $\mathrm{cm}^{-1}$, se han analizado muestras correspondientes a distintos materiales: cera y adhesivo.

La cera está constituida por cera de abejas y el adhesivo por acetato de polivinilo.

\section{Análisis microbiológico}

Los fenómenos de biodeterioro se determinan según las condiciones microclimáticas, en particular la temperatura y la humedad relativa (H.R.) que favorecen el desarrollo de estos organismos y microorganismos. Estas condiciones no son raras en los ambientes en los que se conservan normalmente estas obras; una H.R. superior al $65 \%$ asociada a una temperatura de $20^{\circ} \mathrm{C}$ o superior, es suficiente para causar el desarrollo de microorganismos (bacterias y hongos). Por lo tanto, los microorganismos junto a los insectos, son los biodeteriógenos más frecuentes de las obras de arte que se suelen conservar en este tipo de ambientes.

Con respecto a los materiales, en general los compuestos orgánicos presentes pueden representar una fuente nutricional para un amplio rango de organis-
Fotomicrografía al SEM del hilo metálico original, $75 \mathrm{X}$ 


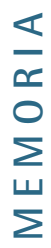

mos y microorganismos heterótrofos. Sin embargo un ataque biológico se da sólo si existen (o han existido) unas condiciones ambientales favorables debido a la falta de control de la humedad y de la temperatura.

Entre los enemigos biológicos encontrados en este caso concreto, deben ser considerados los microorganismos los cuales provocan alteraciones químicas, mecánicas y cromáticas en los soportes. Los daños observados mayoritariamente son los provocados por bacterias y hongos. Estos microorganismos tienen afinidad por los soportes ricos en sustancias proteicas (pergamino, tejidos con fibras de origen animal,...) y celulósicas, respectivamente. El tejido deteriorado está constituido por fibras textiles de algodón y seda.

Se realizó una inspección visual de la obra, en la que se detectaron una serie de manchas en la esquina inferior izquierda. Se observó una evidente degradación del soporte por lo que se procedió a la toma de muestras mediante material estéril. En este caso concreto se trata de detectar la presencia de posibles microorganismos causantes del deterioro del soporte. Para ello se realizaron los cultivos necesarios para su estudio.

Se observaron las muestras al estereomicroscopio, colonias bacterianas y fúngicas, y al microscopio óptico detectándose unas estructuras fúngicas pertenecientes al género Alternaria sp.: micelio fúngico (conglomerado de hifas), y algunas esporas.

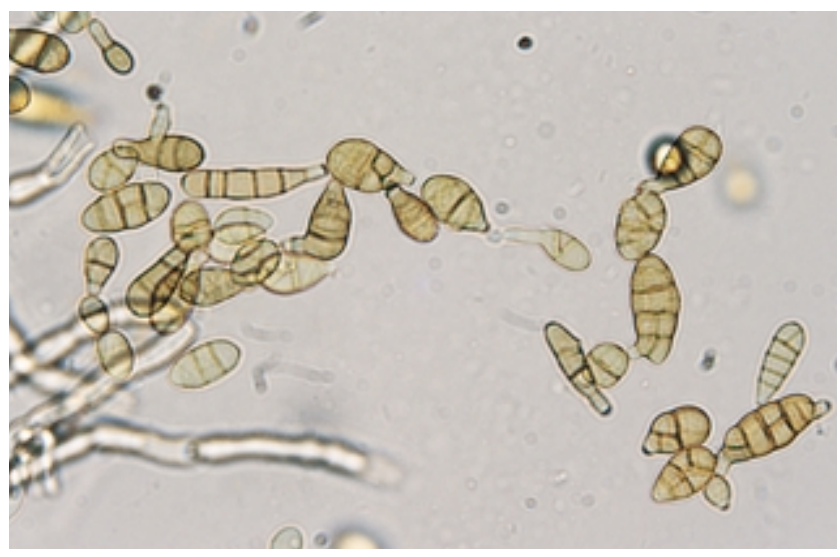

Alternaria sp. Hifas y esporas, 200X

Estos microorganismos, principalmente los hongos causan un daño químico a los soportes en los que se desarrollan debido a las sustancias que excretan al exterior, así como una acidificación del material constitutivo de la obra en estudio. Por otro lado, también pueden ocasionar un daño mecánico por la penetración de las hifas en el sustrato (fibras textiles), lo cual produce una disgregación del material. Debido a la emisión de pigmentos, por parte de estos microorganismos, se observa también un deterioro estético de la obra.

Los microrganismos aislados de la fibra textil de la obra no presentaban actividad en el momento de la intervención. No se observó crecimiento de ninguna colonia sobre el Simpecado. Sin embargo si las condi- ciones ambientales fuesen favorables se produciría el crecimiento de estos microorganismos.

Como tratamiento se aconsejó la aspiración suave y el control de los factores ambientales, temperatura y humedad relativa.

\section{Tratamiento realizado}

Los criterios seleccionados en la intervención del Simpecado han estado condicionados por el grado de degradación, así como por la importancia de las alteraciones que presentaba, tanto en diversidad, como en localización y dimensión. Estos factores han inducido a abordar la actuación desde la perspectiva meramente conservativa, es decir, eliminando al máximo los deterioros existentes y recuperando la lectura integral de la pieza sin recurrir en ningún momento a la reconstrucción total o parcial. Para ello se ha empleado una metodología de trabajo que parte de los resultados de los estudios preliminares efectuados sobre la pieza (históricos, analíticos, características técnicas y diagnóstico) con objeto de aplicar única y exclusivamente los tratamientos mínimos y necesarios que requiere la pieza para devolverle la integridad y unidad perdida.

El estado de conservación y el proceso de intervención ha sido documentado tanto gráfica como fotográficamente con distintas técnicas (macro y micro fotografías, luz rasante, iluminación normal). También se recurrió al estudio radiográfico de los bordados para comprobar la absorción de la radiación de los diferentes hilos metálicos. Esto permitió localizar las zonas en las que aún existían restos de hilos metálicos originales, solapados por los de las intervenciones

Los materiales y tratamientos realizados son reversibles y garantizan la estabilidad sobre la obra sin provocarle nuevas alteraciones.

La intervención se inició con la retirada de la suciedad superficial que presentaba la pieza mediante microaspiración con la ayuda de brochas y pinceles suaves protegiendo las zonas más deterioradas con un tul fijado a un bastidor de madera, evitando de este modo los riesgos de desprendimientos durante este proceso.

Después se separaron de la pieza todos los elementos complementarios: travesaño horizontal, vara vertical, cruz, campanillas y borlones. En el caso de las campanillas se tuvo que eliminar el hilo rojo que las fijaba a la obra.

Posteriormente se empezaron a eliminar las intervenciones anteriores comenzando por el forro y para ello se descosieron las costuras de hilo rojo sintético que lo unían al conjunto, para después poder acceder al armazón interno que se desmontó. Se separaron también las presillas de la parte superior fijadas al terciopelo con hilo rojo. Se retiró la tela blanca de refuerzo del reverso en la que aparecían 

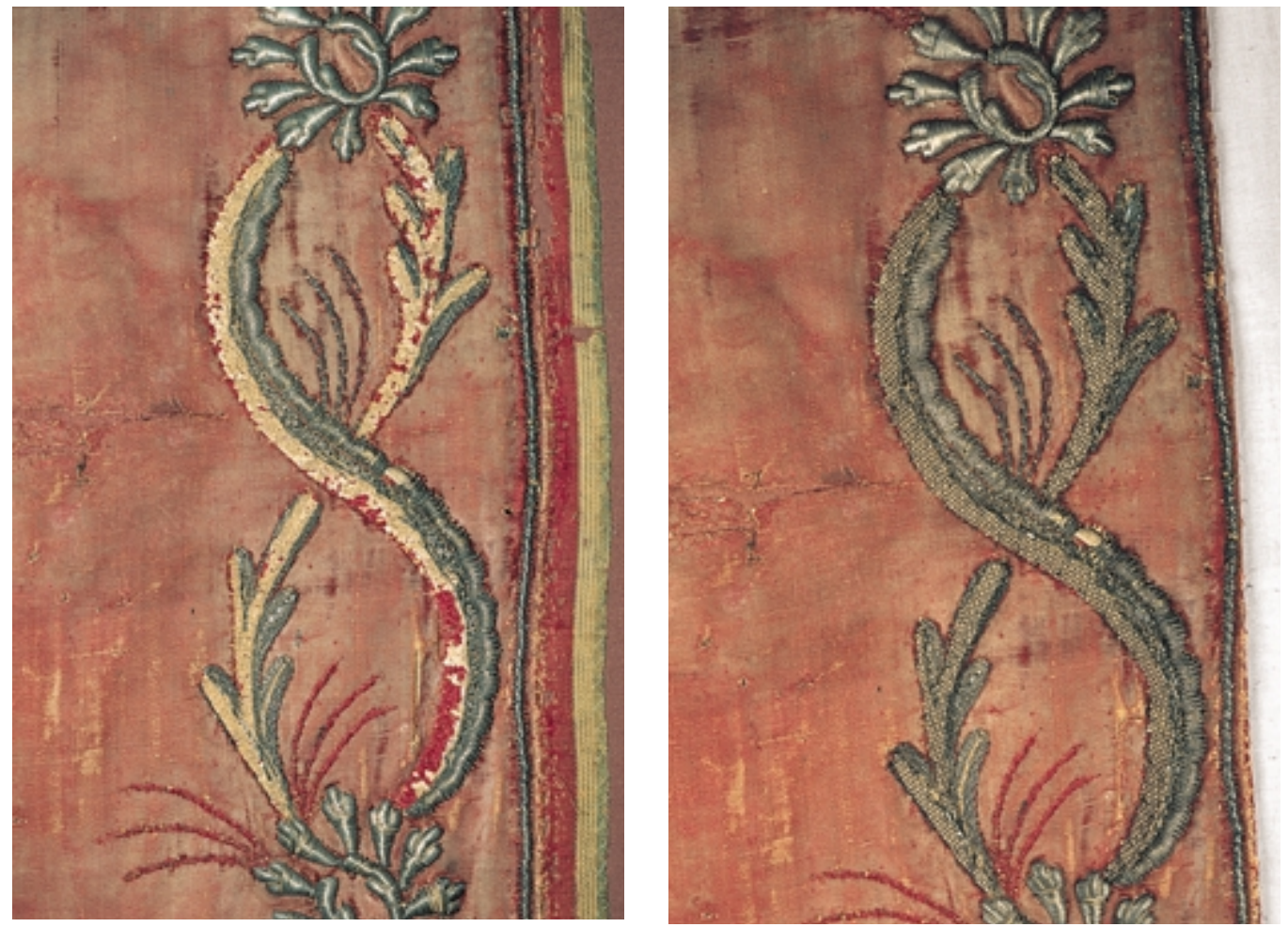

los hilos sintéticos, que fijaban los metálicos del anverso que estaban pegados con cola blanca. Estos hilos se iban cortando conforme se separaba la tela Estaban fijados con mucha tensión y la cola impedía que se pudieran deslizar con facilidad. Se encontró un exvoto que se había introducido entre esta tela blanca y el lino original, que no se desplazaba del lugar en el que se había colocado gracias a los hilos que lo rodeaban. A la vez que se procedía a la separación de la tela blanca se iban levantando los hilos metálicos del anverso, pues al haberse cortado los hilos que los mantenían firmemente fijados al soporte no tenían ya ningún tipo de sujeción al mismo. Con la eliminación estas intervenciones en la decoración, se pudieron recuperar algunos hilos metálicos originales que se encontraban ocultos y que ya se ponían en evidencia gracias al estudio radiográfico. Los injertos que presentaba la pieza también se eliminaron.

También hubo que separar los parches, tanto los del reverso como los internos. Para empezar se trataron los parches que se adherían al lino y que en algunas partes se solapaban unos a otros. Tras realizarse varias pruebas se procedió en primer lugar a la separación mediante el empleo de vapor controlado aplicándose directamente sobre los parches. Una vez que el adhesivo perdía fuerza se retiraban mecánicamente mediante el empleo de pinzas y pequeñas espátulas. Para acceder a los parches internos se abrieron las partes del lino que en su momento fueron cortadas para poder introducirlos. Se aplicó vapor controlado para abrir las diferentes solapas. De este modo y usando pinzas se sacaban poco a poco estos parches también con vapor.
Una vez eliminados todos los añadidos quedaban bastantes restos de cola y para quitarlos se recurrió al empleo de un disolvente adecuado (acetona) después de haber hecho varias pruebas. Se aplicaba sobre el adhesivo hasta que lo ablandaba ligeramente y se trabajaba de un modo rápido para evitar que el disolvente o el mismo adhesivo penetrara en alguno de los tejidos originales. Posteriormente se retiraban los restos de cola mecánicamente. Tan sólo en zonas puntuales también se aplicó vapor controlado sobre la cola poder eliminarla.

Con la espátula caliente se ablandaron los pequeños encontrados en la superficie de la pieza. Los papeles absorbente recogían estos restos y evitaban que la cera penetrase profundamente en el tejido.

Concluidas estas actuaciones se procedió a la limpieza. Después de todos los estudios preliminares efectuados en la obra, se optó por un tipo de limpieza en seco mediante la utilización de un disolvente adecuado (tricloroetileno). Se iba aplicando por toda la superficie y se extraía la suciedad por el reverso colocando papeles absorbentes. En el caso de los bordados la limpieza de los hilos metálicos se realizó de un modo puntual con la ayuda de hisopos humedecidos en agua desmineralizada y unas gotas de etanol al 5\%.

Se pudieron corregir algunas de las deformaciones y pliegues con la aplicación de vapor en algunas zonas ya que las fibras estaban muy resecas. Después se colocaban pesos sobre cristales para eliminar deformaciones.

Posteriormente se procedió a la selección de los diferentes soportes para la consolidación de la obra. Como soporte general de la pieza se utilizaría un algodón
Detalles de la guardilla o greca, antes y después de la matización con tul 


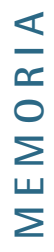

Vista general de la obra antes y después de la intervención

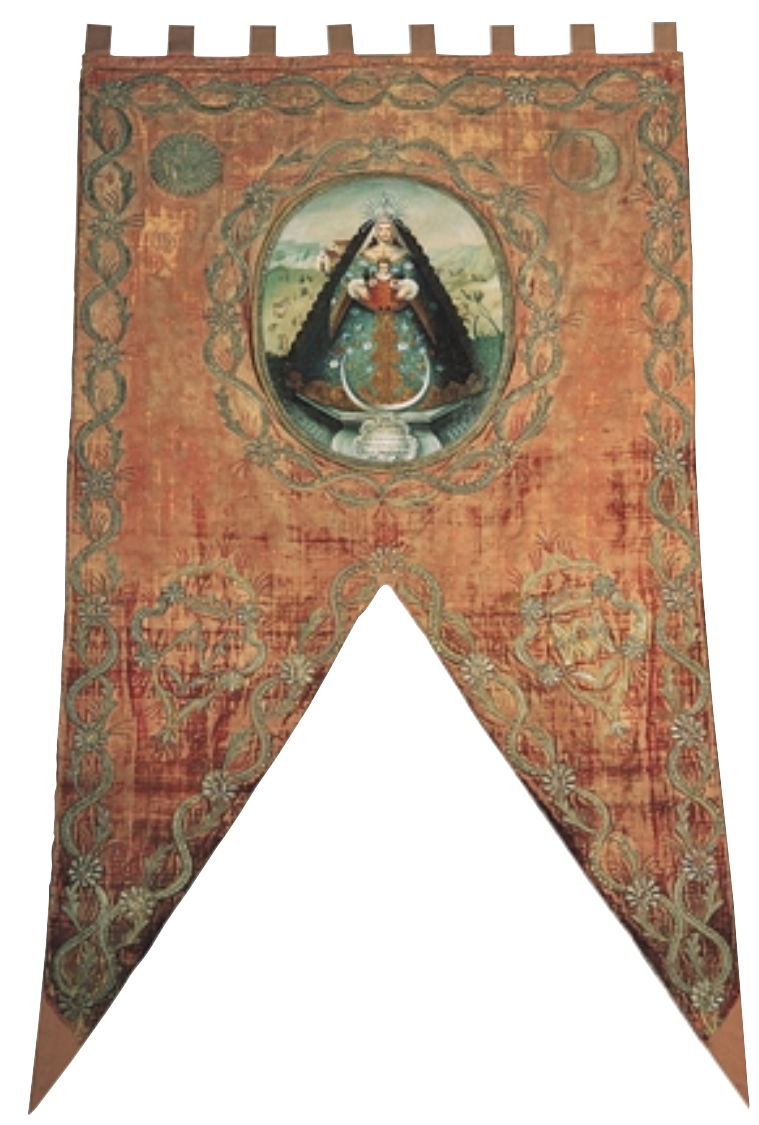

$100 \%$ sin apresto, de color blanco, con técnica de ligamento de tafetán. Este mismo material se utilizó en los soportes locales y en las nuevas presillas. Para la matización de lagunas se optó por las crepelinas y por el tul en los bordados, ambos de seda 100\%. Hilos de seda natural de dos o cuatro cabos se teñirían adecuadamente para ser utilizados posteriormente en el proceso de fijación.

Los tintes empleados eran sintéticos (Ciba Geigy) y tienen garantizada su la estabilidad y la permanencia del color. Se realizaron diferentes pruebas en los distintos materiales hasta llegar al tono adecuado según la zona a tratar.

Para el forro completo con el que se protegió el reverso, se eligió un soporte de seda teñida previamente en color rojizo, adecuado con el conjunto de la obra, sin apresto y técnica de ligamento de tafetán.

Se efectuó después la consolidación de la obra con un soporte general. Este nuevo soporte de algodón elegido se dispuso bajo la obra intentando que el ligamento de la tela coincidiera en la misma posición que el original para evitar deformaciones y pliegues. La consolidación se llevó a cabo mediante líneas de fijación repartidas por toda la obra a intervalos regulares de $15 \mathrm{~cm}$ de separación entre ellas, aproximadamente y siguiendo una disposición escalonada. Después se empezaron a matizar las lagunas de terciopelo bajo las que aparecía el lino. En estas zonas se tuvieron que colocar soportes locales internos de algodón con sus correspondientes crepelinas, teñidos adecuadamente. En las lagunas de terciopelo, bajo las que no llegaba originalmente el estrato de lino, se colocaba simplemente la crepelina sobre el soporte general de algodón.

Se trataron los bordados en aquellas zonas en las que se habían quitado los hilos metálicos de la intervención. Se decide realizar una matización con tul de seda tejido adecuadamente según el lugar en el que se iban a colocar. Estos fragmentos seguirían la forma exacta de la zona del bordado que tenían que recomponer. Si faltaba además el relleno original se disponían fragmentos de batista de algodón fino entonados adecuadamente para reconstruir esas partes y encima se cosía el tul.

Todos los hilos metálicos sueltos de los bordados se fijaron siguiendo siempre la posición que originalmente tenían. Los bordes de las lagunas y los rotos también se fijaron con diferentes tipos de puntos: de escapulario y de restauración según los casos. En estas operaciones se emplearon hilos de seda de dos cabos teñidos del matiz que más se aproximaba al original, utilizando finas agujas curvas para poder trabajar en plano.

El montaje final consistió en colocar las nuevas presillas y el forro del reverso. Para las presillas definitivas se utilizaron varios soportes de algodón forrados con crepelinas de seda. La colocación de las nuevas presillas cumplía tan sólo una función decorativa, para sus- 
tituir a las antiguas que se encontraban bastante deterioradas. Y por último el montaje del nuevo forro de seda del reverso se llevó a cabo mediante costura con hilo de seda.

\section{SISTEMA EXPOSITIVO}

\section{Justificación y necesidad de un sistema expositivo especial}

El Simpecado, como hemos podido apreciar a lo largo de este articulo, es una pieza con unas características técnicas, físicas y conservativas tan complejas y peculiares, que conlleva necesariamente a tener en consideración múltiples factores cuando se trata de definir las mejores condiciones posibles para su presentación al público, sobre todo, si tenemos en consideración su extrema fragilidad y sensibilidad a las variaciones higrométricas del ambiente que lo rodea. Lo que hace necesario establecer unas condiciones climáticas particulares que difieren por lo general, de las del resto de la iglesia, o de cualquier ambiente donde se piense ubicarlo.

Su exposición requiere un estudio exhaustivo que permita hacer compatible la correcta visión de un tejido de estas características, con el respeto hacía las normas conservativas que tenemos que cumplir, puesto que una exposición incorrecta que no tenga en cuenta la tipología y las medidas de la pieza, puede crear un daño irreparable en su estructura al crear tensiones, que con el tiempo, conllevan a deformaciones estructurales permanentes.

Esta obra en particular, por la propia naturaleza y diversidad de materiales que intervienen en su composición, se encuentra catalogadas entre las obras más sensibles y más reactivas a la influencia del ambiente que la rodea, ya que a la naturaleza material del tejido (fibras y tintes), se añade la pintura sobre tabla que decora su parte central.

Teniendo en cuenta estas consideraciones, se plantea como única solución exponer esta pieza en el interior de un expositor que se adecue específicamente a su morfología y características técnicas, y que además mantenga de forma pasiva su estabilidad climática, dando respuesta de esta forma a sus necesidades conservativas.

\section{Exposición}

La primera cuestión que normalmente se plantea a la hora de diseñar un contenedor para obras textiles, es establecer la posición horizontal o vertical del propio expositor. Desde un punto de vista estrictamente conservativo, la exposición horizontal es la más recomendada, sobre todo si tenemos en cuenta las dimensiones y el peso de la obra que nos ocupa. Si bien el propio ámbito expositivo de la obra, sala de museo, interior de una iglesia, etc, suele limitar por exigencias espaciales, la disposición del contenedor (horizontal, vertical o en plano inclinado), es por lo

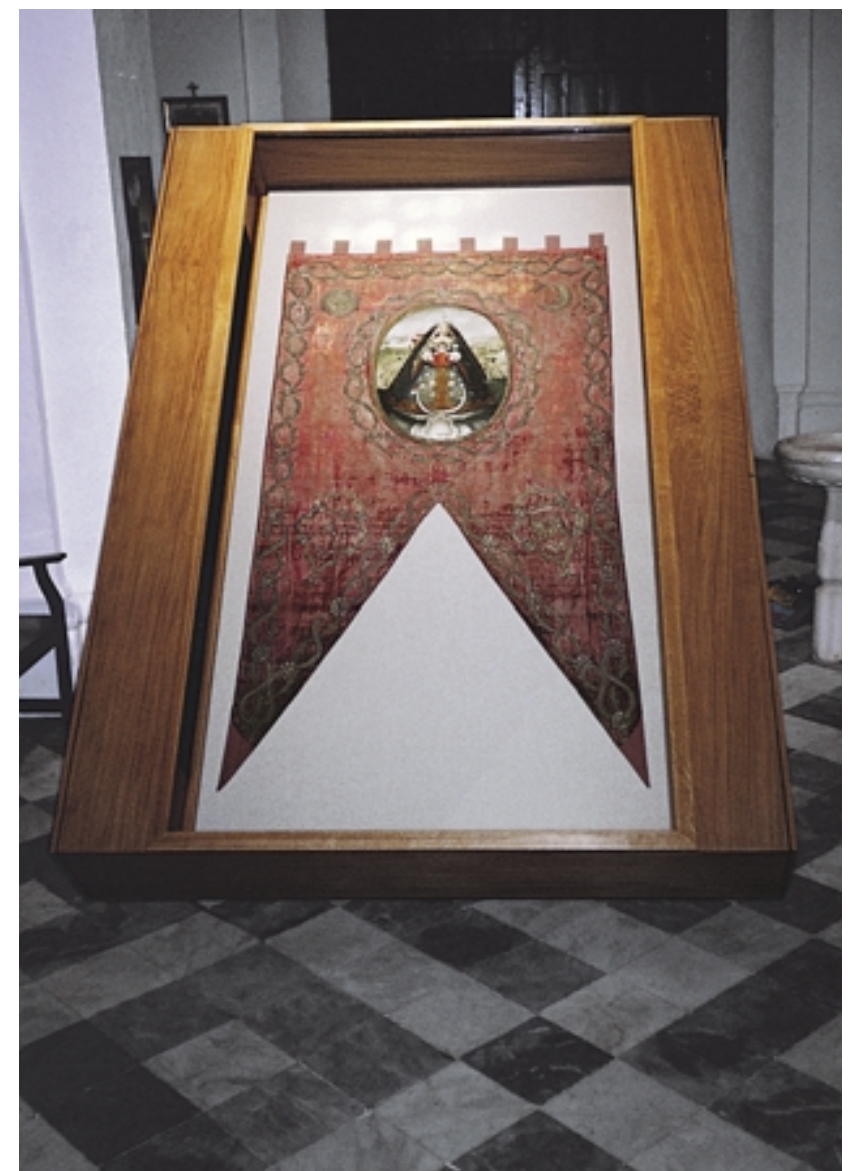

general este factor el que condiciona de forma inevipor parte del espectador.

Siendo por ello necesario que el diseño del expositor sea fruto del estudio de los posibles condicionantes existentes, bien derivados de las necesidades de la obra, o bien derivados de las características del espacio arquitectónico donde se va a ubicar, con un doble objetivo, evitar daños irreparables en la obra y facilitar su correcta visión.

\section{Humedad y temperatura}

El medio ambiente en el que se encuentra expuesto un objeto artístico puede actuar como agente de deterioro tanto de forma directa, provocando o acelerando procesos de alteración en su estructura (humedad, temperatura, iluminación, contaminación etc.), como de forma indirecta, potenciando el desarrollo de otros factores de alteración tales como el desarrollo de microorganismos, ataque de insectos etc.

En el caso específico de esta obra, de naturaleza mixta (tejido más pintura sobre tabla), se hace todavía más importante poder mantener la estabilidad climática del ambiente en el que va a estar expuesta (el propio contenedor), estabilizando su interior a unos niveles de humedad relativa predeterminados (para este tipo de obras se recomienda entre $50-60 \%$ de HR). 


\section{Protección a la luz}

Proteger un tejido de la luz, significa antes de todo, poder eliminar las radiaciones ultravioletas (UV) producidas por la iluminación tanto natural como artificial. La alternativas existentes son diversas: utilizando fuentes luminosas que no emitan U.V., o si se utilizan, filtrándolas adecuadamente.

Pero ello no basta, además, se deben reducir las radiaciones infrarrojas utilizando lámparas especiales que no emitan este tipo de radiaciones.

Por último es necesario reducir al máximo el tiempo de exposición a la luz de estos objetos, al igual que regular la intensidad general de la iluminación en torno a 50 lux.

\section{La acción del polvo}

El deposito de polvo y suciedad sobre cualquier objeto siempre resulta dañino, altera la brillantez natural de los colores, las partículas de polvo y de suciedad penetran en una estructura "acogedora" inherente a las características del propio tejido donde son retenidas por el pelo, constituye un excelente nutriente para cualquier agente microbiológico y además con el tiempo, sus partículas destruyen las fibras cortándolas.

Para evitar que los depósitos y contaminantes del aire puedan interaccionar negativamente con la obra, se deberá pensar en un sistema que actúe como filtro e impida su penetración en el interior del contenedor, al igual que será fundamental prever un programa de mantenimiento y limpieza periódica de la obra.

\section{Proyecto expositivo}

Tras la restauración del Simpecado, se consideró necesario estudiar un prototipo de expositor que diese respuestas a las necesidades conservativas demandadas por una obra con unas características técnicas y morfológicas tan particulares como esta.

En su diseño se ha tenido en cuenta aspectos tales como su estabilidad, seguridad, facilidad de control y de mantenimiento, así como su estética, partiendo para ello de las siguientes premisas:

- Presentación sobre una superficie neutra lisa y uniforme con un ángulo de inclinación mínima de 0 grados y máxima de 40 grados sobre la horizontal para evitar desplazamientos y deformaciones y conseguir de esta forma, una repartición homogénea del peso de la pieza.

- El interior del contenedor que alberga la obra ha de estar climatizado a una humedad relativa estable del $60 \%$. El porcentaje de humedad se ha establecido en base al ambiente del taller de tejidos del Instituto Andaluz del Patrimonio Histórico, lugar donde ha permanecido el Simpecado durante todo el tiempo que ha durado el estudio y su conservación y restauración (aproximadamente un año y medio).
- Las fuentes luminosas del sistema de iluminación seleccionado han de estar ubicadas bien externamente al expositor o bien en compartimentos independientes aislados térmicamente del resto. Con esta disposición evitamos crear desequilibrios térmicos en la zona donde se expondrá la obra, al igual que la emisión de radiaciones nocivas para su conservación.

- Conseguir las condiciones más ideales posibles para la iluminación de esta pieza haciendola compatible con su conservación: no superar los 50 lux, 75 microwatios $\times \mathrm{m}^{2}$ de radiación ultravioleta y temperatura de color de 3100o Kelvin para evitar aberraciones cromáticas y fenómenos de metamerismo en su visión.

- El expositor no ha de estar adosado ni empotrado a un muro para evitar la influencia de las estructura arquitectónica sobre la estabilidad microclimática interna del contenedor.

- Ademas, se ha compatibilizado su función de vitrina de exposición permanente con la de contenedor-vitrina para exposiciones temporales.

\section{Características del sistema expositivo}

La construcción y compartimentación del sistema expositivo deber reunir las siguientes características generales:

- La estructura de base, o soporte, está realizada en un material rígido y resistente. Su función es sostener el contenedor del Simpecado y mantenerlo inclinado en un ángulo variable entre 0 grado y 40 grados sobre la horizontal. Con objeto de hacer este soporte autónomo y facilitar su movilidad, se acopla a su estructura un sistema de rueda para facilitar su desplazamiento.

- El contenedor donde se ubica la pieza debe estar necesariamente acondicionado climáticamente para evitar cualquier influencia directa del medio ambiente circundante que pueda incidir negativamente en su conservación.

- Las dimensiones y el volumen del contenedor están calculados de manera proporcional al tamaño del objeto y a la cantidad de material "tampón" (Art Sorb) necesario para estabilizarlo a los niveles definidos.

- La vitrina será completamente hermética para garantizar su estabilidad microclimática interna, y a la vez, para evitar la penetración de polvo u otros materiales hacia el interior.

El sistema expositivo pensado para el Simpecado, está compuesto por dos partes diferenciadas: Una base que sirve de estructura de sostén y un contenedor que aloja la pieza.

La estructura de sostén, realizada en perfiles metálicos, está compuesta por dos elementos: una cajacontenedor para que resulte mas ligera y resistente a posibles torsiones o flexiones, y un pie de sostén que se ensambla con la estructura metálica de la caja mediante un perno que cumple la función de eje, permitiendo al conjunto, bascular y poder ser bloqueado en la angulación prevista en proyecto.

El interior y el exterior de la caja-contendor está forrado con paneles de aglomerado de media densidad 
(DM) para uso marino. En su ensamblado se ha procurado obtener una hermeticidad necesaria para poder crear un microclima fácilmente controlable. Su construcción se ha realizado respetando los siguientes aspectos técnicos y materiales:

\section{Dimensiones}

La vitrina tiene unas dimensiones de 2,50 $\mathrm{m}$ de largo $\times 1,80 \mathrm{~m}$ de ancho $\times 0,25 \mathrm{~m}$ de profundidad.

Estas dimensiones han sido ajustadas al tamaño del Simpecado, calculando además un borde a su alrededor de $15 \mathrm{~cm}$ que actúa a modo de "paspartout" y permite tener una visión más desahogada de la obra. A estas medidas hay que añadir $20 \mathrm{~cm}$ en cada lateral longitudinal para crear el alojamiento del sistema de iluminación seleccionado (guía de luz).

\section{Plano de apoyo del Simpecado}

El plano de fondo de la vitrina está provisto de un contra panel deslizante del mismo tamaño que el fondo de la vitrina y de $15 \mathrm{~mm}$ de espesor que permite manipular el Simpecado sin tocar en ningún momento el tejido original. El material utilizado para la construcción del plano es "MAKROLON celular" un policarbonato totalmente inerte que no tiene ningún tipo de dilatación ni de contracción.

Este panel ha sido revestido con paneles de Art-Sorb acondicionado a una humedad relativa de un $60 \%$, a fin de poder obtener unas condiciones climáticas adecuadas para esta pieza.

El Art-Sorb, como bien se sabe, es un regulador de humedad para la conservación de obras de arte de altas prestaciones. Se utiliza para crear microclimas apropiados para los objetos instalados en vitrinas. Amortigua las variaciones de humedad relativa y asegura una humedad constante. Los cambios de humedad se producen con mucha mas suavidad que con el gel de sílice de densidad normal.

\section{Forro del soporte:}

Por encima del Art-Sorb y recubriendo toda la superficie del soporte, se ha colocado un forro constituido por dos estratos diferentes. El inferior, realizado con muletón suizo de algodón 100\%, como material amortiguante, proporciona una superficie lisa y uniforme a la pieza. El superior, sobre el que descansa el Simpecado, está realizado en batista de algodón 100\% teñida de un color que entona con la tonalidad general de la obra al mismo tiempo que la pone en evidencia.

\section{Fijación}

Para evitar desplazamientos del Simpecado una vez colocado sobre la batista de algodón, han sido previs- tos unos puntos de fijación en Velcro que evitan cualquier tipo movimiento imprevisto.

\section{Cierre y visionado del expositor:}

La parte anterior de la vitrina presenta un cierre acristalado para permitir la perfecta visión de la obra.

Las guías laterales, previstas para el alojamiento de la plancha de policarbonato transparente utilizada para el acristalamiento, están forradas con una espuma especial de media densidad de Poliuretano de tipo estere, que evita rozamiento y desgaste en la puesta en obra de la misma, al mismo tiempo que permite la hermeticidad de la parte frontal de la vitrina y amortigua el peso del policarbonato que se utilizará para cerrar el expositor.

La elección del policarbonato como tapa transparente se justifica por las características inherentes de este material entre la que destacamos:

- No suministra reflejos coloreado, alta resistencia a los golpes, presenta optimas propiedades mecánicas, térmicas y químicas, no se altera en presencia de gas, tiene un peso con un espesor de $16 \mathrm{~mm}$ notablemente inferior a un cristal blindado o a un cristal laminar (alrededor de $60 \mathrm{~kg}$ ) en comparación con los $120 \mathrm{~kg}$. de los otros materiales citados.

- Para las dimensiones previstas que son de 3,5 $\mathrm{m}^{2}$, mantiene una transparencia muy elevada (alrededor de un $89 \%$ ), lo cual permite una perfecta visión del objeto expuesto, cromáticamente hablando. La perdida de transparencia después de 5 años de exposición al exterior es inferior al $1 \%$ del valor de transmisión inicial.

- No crea aberraciones cromáticas típicas de un cristal o un vidrio (tonalidad verdosa) que en el espesor previsto $(16 \mathrm{~mm}$ ) habría suministrado una fuerte dominante verde que alteraría considerablemente el extraordinario cromatismo de la obra

- Por ultimo es de reseñar su facilidad de trabajo con herramienta normales, así como el ensamblado de piezas mediante soldadura, encolado o atornillado

Su empleo permite además de las ventajas aportadas por el propio material ya expresadas, que el expositor cumpla una doble función: proteger de forma simple el Simpecado contra posibles actos vandálicos y facilitar la visión de la pieza sin deformaciones cromáticas.

Y también, evitamos la incidencia de las radiaciones que se pueden producir en el ambiente donde estará expuesto (mixta -natural y artificial-), ya que este material es por si mismo un filtro contra las radiaciones aportadas por el sistema de iluminación o del ambiente circundante que pueden afectar de forma nociva a una obra de arte (ultravioletas e infrarrojas).

\section{Sistema de iluminación}

El sistema de iluminación, expresamente pensado y diseñado para este expositor está compuesto de 2 "guías de luz a emisión prismática" dispuestas de manera para- 


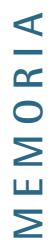

lela al Simpecado en unos alojamientos especialmente diseñados en los laterales longitudinales del contenedor.

Esto sistema de iluminación reúne las siguientes características técnicas:

- La fuente de iluminación tiene un elevado índice de eficiencia cromática, aproximadamente de un 3.100 grados Kelvin, (valor considerado ideal para observar una obra de arte).

Este hecho hace que el cromatismo de la obra no sea interferido por las variaciones de temperatura de color procedentes de la fuente luminosa, pudiendose apreciar correctamente tanto las tonalidades frías (azules) como las cálidas (rojos).

- Limitación del estrés microclimático inducido por la fuente luminosa (la iluminación no aporta calor a la pieza).

- La fuente luminosa cumple las recomendaciones internacionales para la exposición de objetos tan singulares como el que nos ocupa (niveles de iluminación necesario para exponer este tipo de material), que son de 50 lux limitando el tiempo de exposición.
- Soluciona las exigencias conservativas de iluminación en cuanto que se elimina completamente la radiación ultravioleta (mecanismo de degradación imputable a la luz), y de consecuencia, disponer de la posibilidad de someter a las obras de arte a unos niveles de iluminación superiores a los normalizados a nivel internacional sin ocasionar daños en ellas.

\section{Conclusiones finales}

La importancia de este proyecto estriba en el hecho de poder exponer al público, una obra tan frágil como es el Simpecado, con plena garantía para su conservación. Gracias a los medios técnicos y científicos que tenemos a nuestra disposición se ha podido idear un contenedor expositivo que cumple tanto con la normas de conservación preventiva, como con los fines museográficos. De hecho conservar no significa descontextualizar la obra de arte sino buscar soluciones lógicas a problemas complejos.

\section{Bibliografía del sistema expositivo}

A.A.V.V. I supporti nelle Arti pittoriche. Storia, tecnica, restauro. ed. Mursia. |99|, p:30| - 313 .

C. DANTI, R. BODDI, A. CRESCIOLI. "Progetto e realizzazione de sistema espositivo per la conservazione di un rilievo del Museo Bardini in Firenze attribuito a Donatello". Actas del Congreso de Pruebas no destructivas. Paraguay 1990,p: IV/7.I - IV/7.I4

Mª. GONZÁLEZ Y R. BAGLIONI " Asesoramiento técnico sobre la problemática actual de conservación del tríptico denominado "del Gran Capitán", esmalte perteneciente a los fondos del Museo de Bellas artes de Granada". Informe Interno del IAPH. 1993.

R. BAGLIONI "Proyecto de sistema expositivo para la Bandera de la Batalla de las Navas de Tolosa, Vilches, Jaen" Informe interno del IAPH. Enero de 1997.

R. BAGLIONI " Vitrina de conservación del esmalte denominado "Tríptico del Gran Capitán" del Museo de Bellas Artes de Granada. Proyecto y realización". Boletín del Instituto Andaluz del Patrimonio Histórico Nª I año IV, Junio 1996, p: 75-82

F. ARAMINI. lluminación y estudios colorimétricos aplicados a la exposición del bien cultural". Extraído de Un proyecto para la Capilla Real de Granada. Serie Cuaderno n I, p: 77-80.

\section{A.A.V.V. "Museum-Vitrines", Nº 46 Paris, 1985}

M. BACCAREDDA BOY. Materie plastiche ed elastomeri. Quaderni di chimica applicata, a cura di E.Mariani. ED.Ambrosiana 1976. P: I56-167 M. C. BERDUCOU. La conservation en Archéologie. Ed. Masson. 1990. G. DE GUICHEN. Climat dans le Musée. ICCROM. 1984.

G. PAULILLI. "L' illuminazione ecologica". Media Production, $n^{\circ} 64$. 1995, p: |6-2|.

P. RADI. "II sistema d' iluminazione a Guide di Luce". Luce, anno 32, $n^{\circ} 2$, marzo/aprile. 19993, p: 68-72.

H. SAECHTLING. Manuale delle materie plastiche $3^{\text {a }}$ edizione. Tecniche Nuove, Milano 1986

N. STOLOW. Conservation and Exhibitions. Butterworths. 1987.

G. VANNUCCHI. Ottica integrata e microottica, vol I y 2. Ed. Pátron. 1982.

VILLAVECCHIA-EIGERMANN. Nuovo dizionario di merceologia e chimica applicata. Milano, 1975, P: 2528-2529.

Equipo de trabajo

Estudio Histórico Artístico:

Gabriel Ferreras Romero. Historiador. Dpto. de Investigación. Intervención de Conservación-Restauración:

Lourdes Fernández González. Restauradora de Tejidos Dpto. de Tratamiento. Centro de Intervención del IAPH.

Intervención de Conservación-Restauración:

Rocío Magdaleno Granja. Restauradora de Pintura. Dpto. de Tratamiento. Centro de Intervención del IAPH.

Análisis químico:

Francisco Gutiérrez Montero. Asesor Técnico Laboratorio. Centro de Intervención del IAPH.

Análisis químico:

Lourdes Martín García. Química del departamento de Análisis. Centro de Intervención del IAPH.
Análisis biológico:

Marta Sameño Puerto. Bióloga del departamento de Análisis. Centro de Intervención del IAPH.

Fotografía:

Eugenio Fernández Ruiz. Fotógrafo. Dpto de Análisis. Centro de Intervención del IAPH.

Estudio y diseño del proyecto expositivo:

Raniero Baglioni. Consevador - restaurador. Sector de Conservación Preventiva. Centro de Intervención del IAPH.

Dirección y Coordinación:

Pedro Castillo Pérez. Jefe del Departamento de Tratamiento. Centro de Intervención del IAPH. 